\title{
WestVirginiaUniversity
}

THE RESEARCH REPOSITORY @ WVU

Graduate Theses, Dissertations, and Problem Reports

2009

\section{Impact of injecting inert cushion gas into a gas storage reservoir}

Sudheer R. Lekkala

West Virginia University

Follow this and additional works at: https://researchrepository.wvu.edu/etd

\section{Recommended Citation}

Lekkala, Sudheer R., "Impact of injecting inert cushion gas into a gas storage reservoir" (2009). Graduate Theses, Dissertations, and Problem Reports. 2005.

https://researchrepository.wvu.edu/etd/2005

This Thesis is protected by copyright and/or related rights. It has been brought to you by the The Research Repository @ WVU with permission from the rights-holder(s). You are free to use this Thesis in any way that is permitted by the copyright and related rights legislation that applies to your use. For other uses you must obtain permission from the rights-holder(s) directly, unless additional rights are indicated by a Creative Commons license in the record and/ or on the work itself. This Thesis has been accepted for inclusion in WVU Graduate Theses, Dissertations, and Problem Reports collection by an authorized administrator of The Research Repository @ WVU. For more information, please contact researchrepository@mail.wvu.edu. 


\title{
IMPACT OF INJECTING INERT CUSHION GAS INTO A GAS STORAGE RESERVOIR
}

\author{
Sudheer R Lekkala \\ Thesis Submitted to the College of Engineering and Mineral Resources at \\ West Virginia University in Partial Fulfillment of the \\ Requirements for the Degree of \\ Master of Science \\ In \\ Petroleum \& Natural Gas Engineering \\ Committee \\ Kashy Aminian, Ph.D., Chair \\ Samuel Ameri, M.S \\ IIkin Bilgesu, Ph.D
}

Department of Petroleum \& Natural Gas Engineering

Morgantown, West Virginia

2009

Keywords: Natural Gas, Underground Storage, Injection of cushion gas, replacement of cushion, Nitrogen as cushion, inert cushion gas, I/W cycles, mixing in storage, pipeline quality gas 


\begin{abstract}
IMPACT OF INJECTING INERT CUSHION GAS INTO A GAS STORAGE RESERVOIR

(Sudheer Reddy Lekkala)
\end{abstract}

Underground natural gas storage is a process which ensures constant supply of natural gas by storing the excess gas produced and quickly supply when required. The underground storage makes use of depleted reservoirs to store the natural gas. Cushion gas assists in delivering the natural gas (working gas) and maintains the adequate pressure in the reservoir. The key issue is that cushion gas cannot be produced and remains as a permanent inventory which accounts to about $30 \%$ of development cost in a typical storage reservoir. A part of cushion gas may be replaced with an inert gas such as nitrogen or carbon dioxide to reduce the investment cost.

The impact of replacing the cushion gas by nitrogen was studied by simulating nitrogen injection into a storage reservoir. The technical difficulty in replacing the cushion by nitrogen is the mixing which would corrupt the quality of natural gas. Some mixing is unavoidable when two dissimilar gases come in contact, but could be controlled with close monitoring and strategic planning. The reservoir parameters such as porosity, permeability and pressure were varied to study the mixing trends. Storage reservoirs are usually considered to serve for long time periods and therefore multiple withdrawal and injection cycles were simulated to study the mixing trend in detail. Different scenarios were considered in simulation by altering well placement, reservoir shape, injection of nitrogen in stages, and distance between the injector and producer wells.

It has been found that the optimum percentage of cushion that can be replaced by nitrogen gas is 20 . The degree of mixing is function of withdrawal rate and the fraction of cushion gas replaced in the storage reservoir. Reservoir pressure and permeability may affect the degree of mixing in early cycles but do not have significant impact on mixing. Reservoir porosity appears to have minor impact on the mixing. The mixing effect decreases to a great extent if distance between the producer well and the nitrogen injector is increased. 


\section{ACKNOWLEDGEMENTS}

It is a pleasure to express my gratitude to my research advisor Dr.Kashy Aminian for providing me an opportunity to work on this topic. I would like to thank him for his valuable guidance, encouragement and support throughout this work. I would like to extend my thanks to my other two committee members Dr.IIkin Bilgesu and Dr.Samuel Ameri, who also is the chair of Petroleum \& Natural Gas Engineering department for being a part of my research. I would also like to thank Dr.Shahab Mohaghegh and other faculty for their help during the course of my study.

There needs to be a special mention for Ms.Beverly Matheny who has helped with the administrative matters. Thanks to my friends for helping me during the course of study. 


\section{TABLE OF CONTENTS}

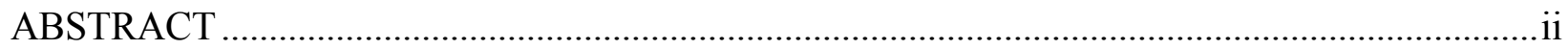

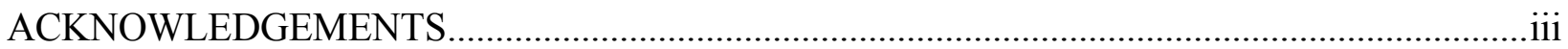

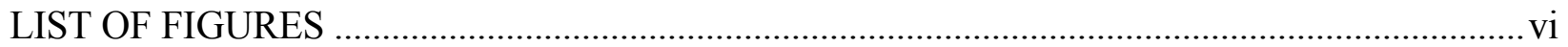

LIST OF TABLES …..........................................................................................................

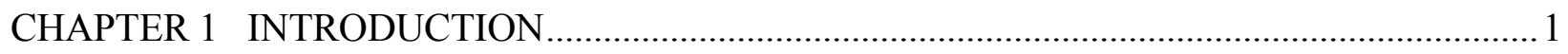

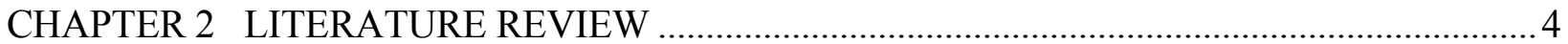

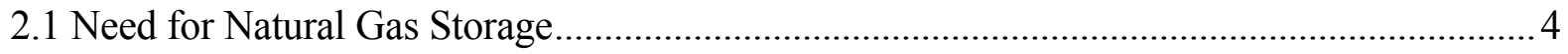

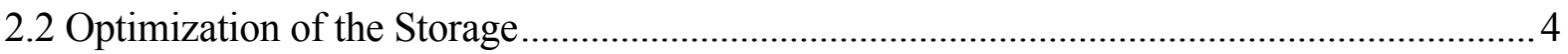

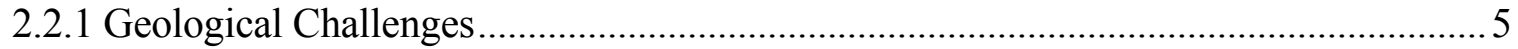

2.2.2 Reduction of Cushion Gas Investment ..................................................................... 5

2.3 Factors influencing Mixing between Inert Cushion and Natural Gas ................................. 6

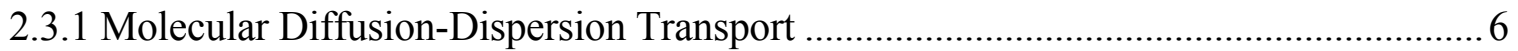

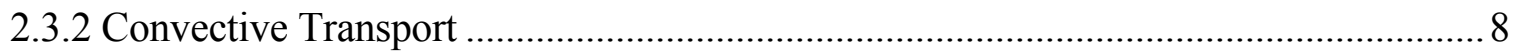

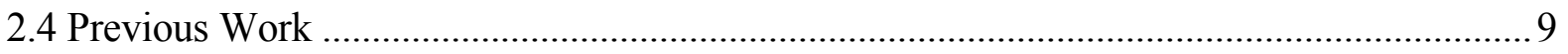

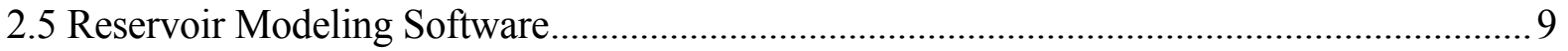

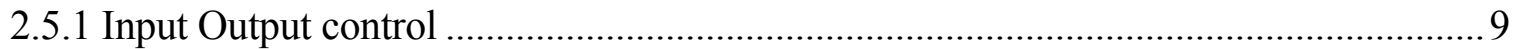

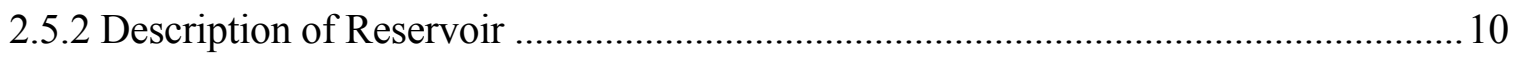

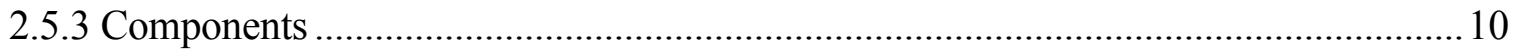

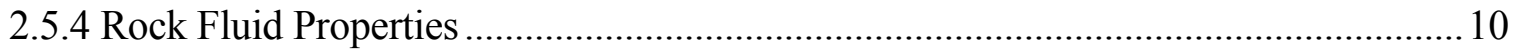

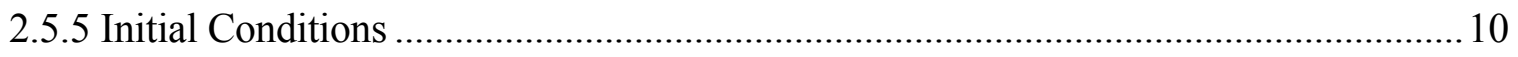

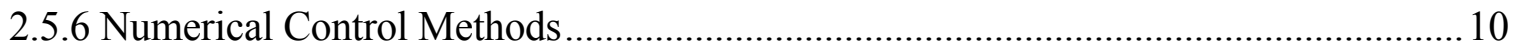

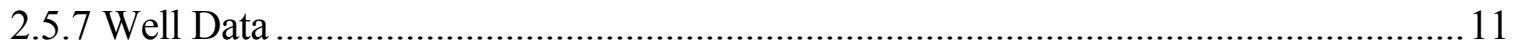

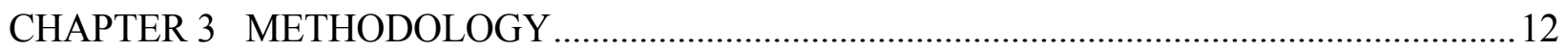

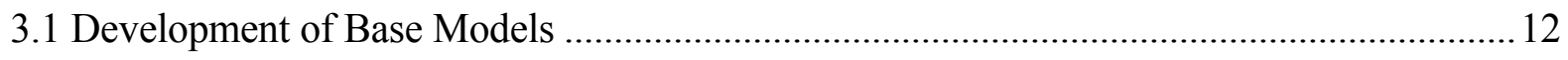

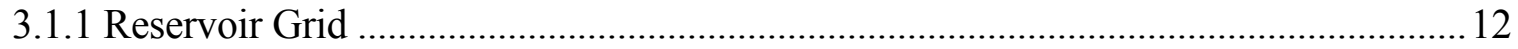

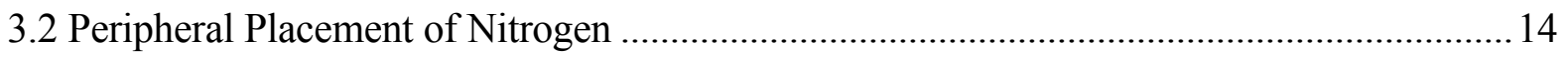

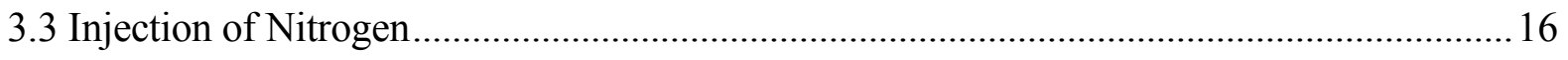


3.3.1 Injection Withdrawal Cycles ................................................................................... 18

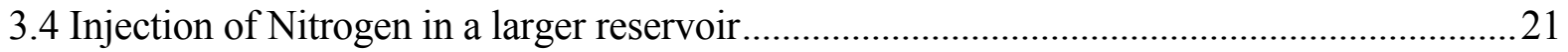

3.5 Injection of Nitrogen in a rectangular reservoir grid .......................................................2.

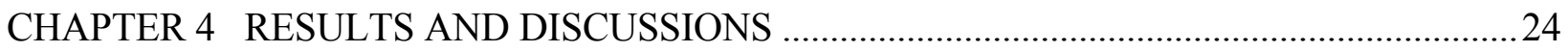

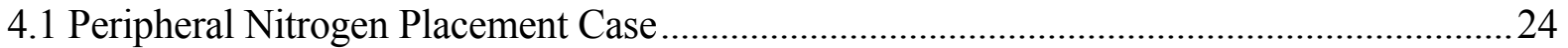

4.1.1 Effect of mixing on variation in percentage of Nitrogen cushion in reservoir ...........24

4.2 Injection of Nitrogen through diagonal placement of wells .................................................22

4.2.2 Effect of Pressure on Mixing in the Reservoir ...........................................................22

4.2.3 Effect of Porosity on Mixing in Reservoir..................................................................30

4.2.4 Effect of Permeability on Mixing in Reservoir .........................................................32

4.3 Distance variation between Injector and producer well........................................................34

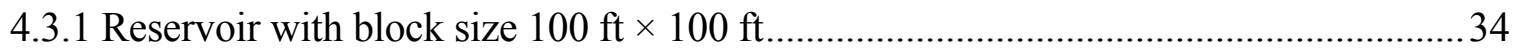

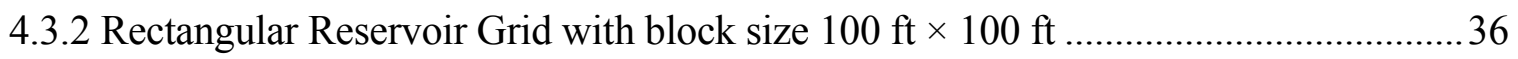

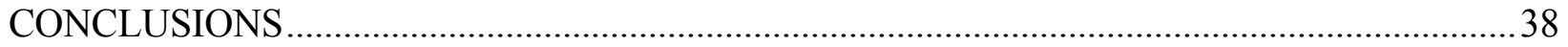

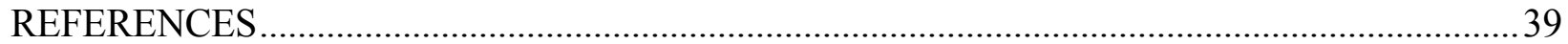




\section{LIST OF FIGURES}

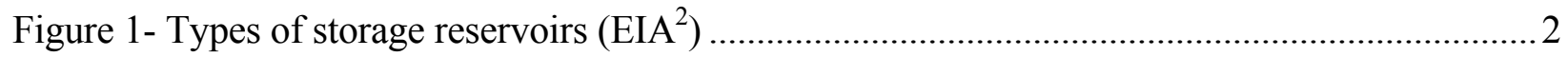

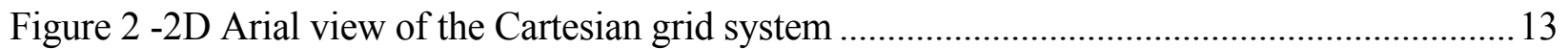

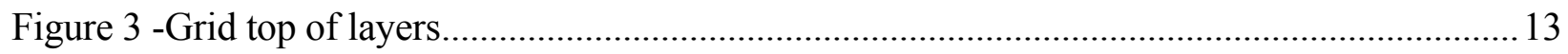

Figure 4 -Nitrogen distributed in outer layer 10\% by Volume...................................................... 14

Figure 5 -Nitrogen distributed in two outer most layers $20 \%$ by Volume ........................................ 15

Figure 6- The diagonal well placement of nitrogen injector and methane producer. ........................ 17

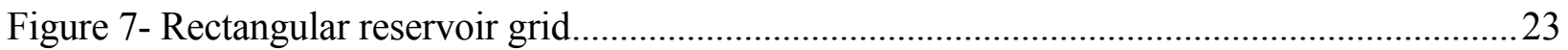

Figure 8- Mole \% of Nitrogen in the Withdrawn Gas $\left(10 \% \mathrm{~N}_{2}\right.$ by Volume) ……….........................2

Figure 9 - Mole $\%$ of Nitrogen in the Withdrawn Gas $\left(20 \% \mathrm{~N}_{2}\right.$ by Volume) ....................................2

Figure 10- Mole $\%$ of Nitrogen in the Withdrawn Gas ( $10 \% \mathrm{~N}_{2}$ Injected by Volume) ....................26

Figure 11- Mole $\%$ of Nitrogen in the Withdrawn Gas ( $20 \% \mathrm{~N}_{2}$ Injected by Volume) ...................2 27

Figure 12- Mole \% of Nitrogen in the Withdrawn Gas $\left(10 \% \mathrm{~N}_{2}\right.$ Injected by Volume - Reservoir

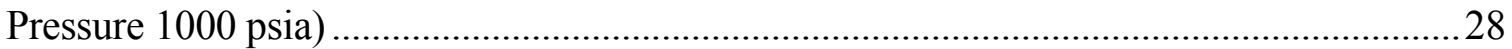

Figure 13- Mole \% of Nitrogen in the Withdrawn Gas $\left(10 \% \mathrm{~N}_{2}\right.$ Injected by Volume - Reservoir

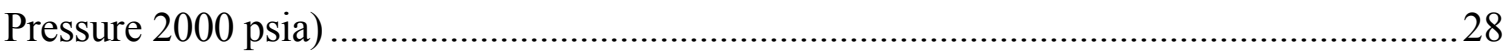

Figure 14- Mole \% of Nitrogen in the Withdrawn Gas $\left(20 \% \mathrm{~N}_{2}\right.$ Injected by Volume - Reservoir

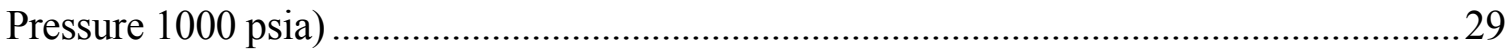

Figure 15- Mole \% of Nitrogen in the Withdrawn Gas $\left(20 \% \mathrm{~N}_{2}\right.$ Injected by Volume - Reservoir

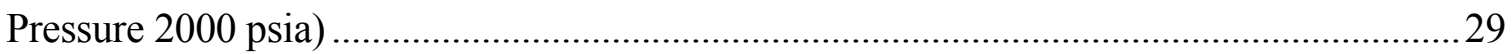

Figure 16- Mole \% of Nitrogen in the Withdrawn Gas - 10\% Reservoir Porosity .............................30

Figure 17- Mole \% of Nitrogen in the Withdrawn Gas - 20\% Reservoir Porosity ............................ 31

Figure 18- Mole \% of Nitrogen in the Withdrawn Gas - 30\% Reservoir Porosity ............................ 31

Figure 19- Mole \% of Nitrogen in the Withdrawn Gas - Reservoir Permeability $100 \mathrm{md}$..................32

Figure 20- Mole \% of Nitrogen in the Withdrawn Gas - Reservoir Permeability 200 md.................33

Figure 21- Mole \% of Nitrogen in the Withdrawn Gas - Reservoir Permeability 300 md.................33

Figure 22- Mole \% of Nitrogen in the Withdrawn Gas (10\% N2 Injected into a Large Reservoir) 35 Figure 23- Mole \% of Nitrogen in the Withdrawn Gas (10\% N2 Injected into a Rectangular

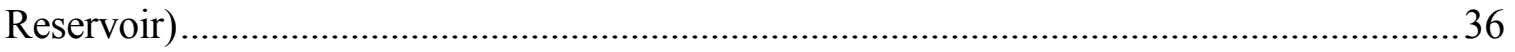




\section{LIST OF TABLES}

Table 1 - Distribution of Components in Peripheral Nitrogen Placement Models 16

Table 2 - Component distribution and withdrawal rate in Peripheral Nitrogen Placement Models. 16

Table 3 - Injection of Nitrogen - Division of cases based on amount of nitrogen injected............... 18

Table 4 - Withdrawal and Injection scenarios............................................................................. 19

Table 5 - Case 1 - Distribution of components and withdrawal rate at different pressures ...............19

Table 6 - Case 2 - Distribution of components and withdrawal rate at different pressures...............20

Table 7 - Case 1 - Distribution of components and withdrawal rate at different permeability ........20

Table 8 - Case 1 - Distribution of components and withdrawal rate for different porosity ..............21

Table 9 - Case 2 - Distribution of components and withdrawal rate for different porosity ...............21

Table 10 - Distribution of components and withdrawal rate at different pressures for model of

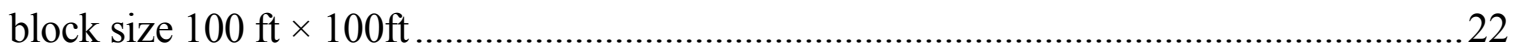

Table 11 - Distribution of components and withdrawal rate for model of block size $200 \mathrm{ft} \times 200 \mathrm{ft} 22$

Table 12 - Distribution of components and withdrawal rate for rectangular reservoir grid .............23

Table 13 - Material balance of Nitrogen with different percentages of total volume........................24

Table 14 - Nitrogen material balance for different porosities...........................................................

Table 15 - Nitrogen material balance for varying permeability ......................................................... 32

Table 16 - Nitrogen material balance for increased block width of $100 \mathrm{ft}$.........................................34

Table 17 - Nitrogen material balance for rectangular grid of same volume.......................................36 


\section{CHAPTER 1}

\section{INTRODUCTION}

Natural Gas is a vital component of the world's supply of energy. It is one of the cleanest, safest, and most useful of all energy sources ${ }^{1}$. The use of underground gas storage is important in ensuring the consistent supply of natural gas. The key to smooth this process is to be able to store large quantities of gas produced during periods of low demand and supply quickly when required in peak demand. The excess natural gas produced is injected into large underground reservoirs and supplied when the demand for gas exceeds supply, for instance the commercial and residential facilities need natural gas in peak winter for heating purposes or during hot summers for air conditioning which is met by withdrawing natural gas from storage reservoirs. The storage reservoirs need certain amount of gas (Cushion gas) to support the withdrawal by maintaining adequate pressure to deliver quickly when desired by the market ${ }^{2}$. The rate at which the gas is withdrawn depends on the demand and the capacity of reservoir. Cushion gas is volume of gas intended as a permanent inventory and only a small part of it could be produced along with the withdrawn gas (Working gas).

Natural gas is usually stored underground, in large storage reservoirs ${ }^{3}$. There are three main types of underground storage are (1) Depleted reservoirs in oil and/or gas fields, (2) aquifers, and (3) salt cavern formations. There have been efforts to use abandoned mines to store natural gas,

with at least one such facility having been in use in the United States in the past ${ }^{4}$. The potential for commercial use of hard-rock cavern storage is currently undergoing testing. The two most important characteristics of an underground storage reservoir are its capacity to hold natural gas and the rate at which gas inventory can be withdrawn-its deliverability rate ${ }^{5}$. Figure 1 shows the representation of different types of gas storage facilities. Each storage facility is different in its own way and desired storage type can be employed by one's criteria such as capacity, deliverability, feasibility of access and economic advantage. 


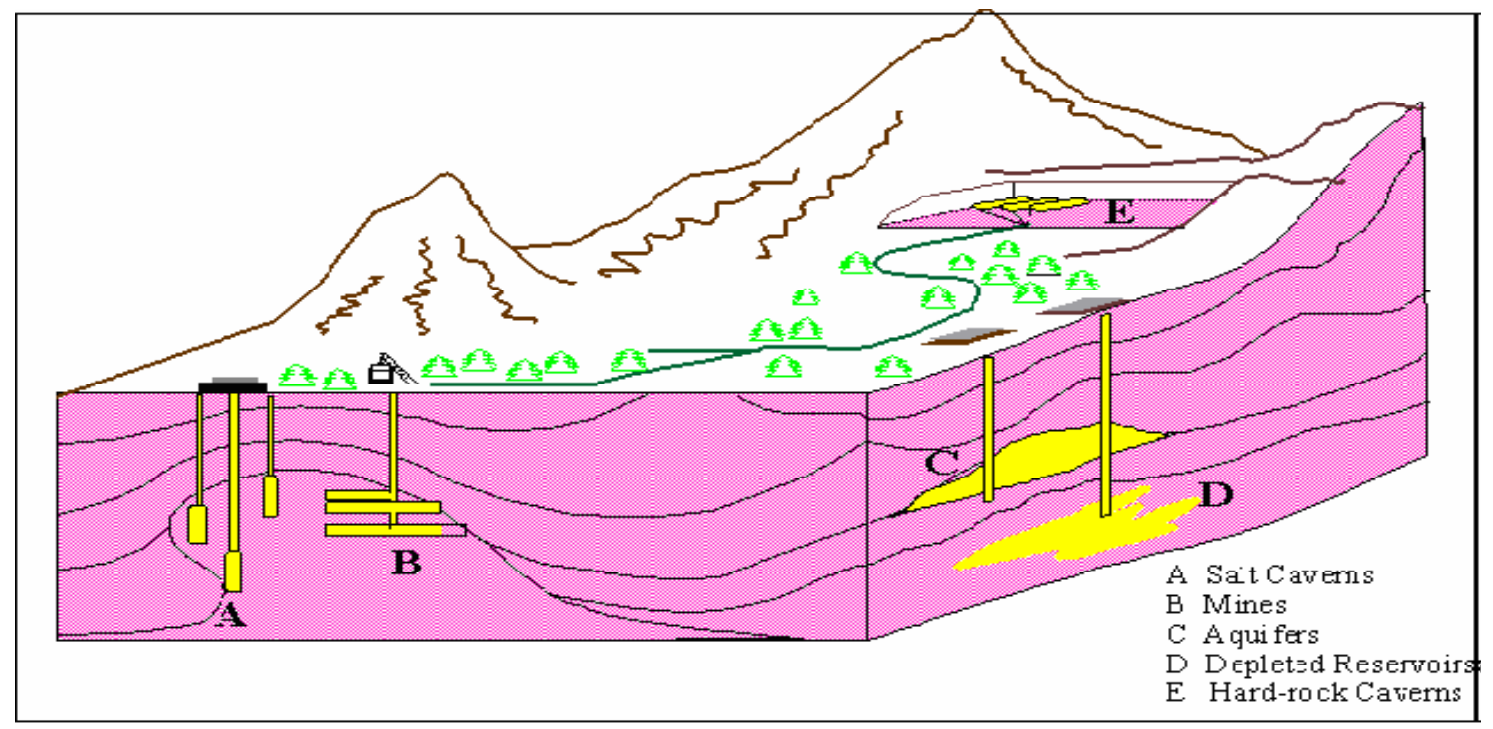

Figure 1- Types of storage reservoirs (EIA $\left.{ }^{2}\right)$

The importance of storing gas has increased despite the recent decline in the consumption because of the temperature sensitivity which increased the demand in the residential and commercial sectors. The most common form of underground storage consists of depleted gas reservoirs ${ }^{6}$. Depleted reservoirs are those formations that are abandoned after the production of all available hydrocarbons. The factors that determine whether or not a depleted reservoir will make a suitable storage facility are both geographically and geologically driven. Geologically the depleted reservoir formations must have high permeability and porosity. The porosity of the formation determines the amount of natural gas that it may hold, and its permeability determines the rate at which natural gas flows through the formation. Permeability also contributes to determine the rate of injection and withdrawal of working gas ${ }^{7}$. Geographically the depleted reservoirs should be near consuming centers so that large pipeline construction and maintenances could be avoided. In addition to these the depleted gas reservoirs can make use of existing wells, gathering systems and piping facilities present which are already filled with hydrocarbons and leaves minimal or no chances of leak ${ }^{8}$. 
Most commonly part of cushion gas in the storage field remains as a permanent inventory and not produced along withdrawn gas, it is not normally cycled during operation which accounts to major fraction of the total expenditure in developing a storage reservoir ${ }^{9}$. Current existing storage fields use natural gas as base gas which has been already purchased and depreciated. The prices of natural gas being unpredictable and the possibility of being not able to use the base gas in operation put the investors to think of an ideal solution through research. The use of any less expensive gas as an alternative to substitute part of cushion gas could substantially reduce the investment cost ${ }^{(10,11 \text { and } 12)}$. The inert gas such as nitrogen which is abundant would be a good substitute and the price differential between natural gas and nitrogen would come as a great economic incentive to the investors ${ }^{13}$.

This study focuses on long-term benefits of using nitrogen to replace a part of the cushion gas. The key issue in using nitrogen as partial replacement for cushion gas is mixing between the inert gas and natural gas, which would corrupt the quality of natural gas. The storage reservoir is to be designed and replacement of cushion gas is done such that mixing is minimized. Optimum percentage of the cushion that can be replaced is determined by using a three dimensional model of reservoir to study the impact of porosity, permeability and pressure on mixing. Some amount of mixing is unavoidable when two miscible gases come into contact, but the percentage of the inert nitrogen must be controlled in withdrawn gas by close monitoring. Even if the withdrawn gas contains nitrogen beyond the allowable percentage, the separation techniques are to be used to ensure the supply of quality gas. The objective of the study is to replace maximum percentage of cushion without affecting the quality of pipeline gas. The study also involves the controlled injection of nitrogen over a long time to estimate the optimum amount of cushion that could be replaced. 


\section{CHAPTER 2}

\section{LITERATURE REVIEW}

\subsection{Need for Natural Gas Storage}

The natural gas demand is highly cyclical. Periods of high demand occur during winters are met with natural gas stored underground typically during warmer months when demand is lower. Natural gas is commonly injected in to storage during April through October for use during winter.

The approximately 400 underground natural gas storage facilities located strategically throughout the United States are key to maintaining the reliability, integrity, and capability of the Nation's natural gas transmission and distribution network. Peak working gas storage capacity as of mid-2008 is 3,789 billion cubic feet (Bcf), an increase of $86 \mathrm{Bcf}$ from last year ${ }^{14}$. The advantages of storing natural gas are listed as follows,

1. The continuity of gas supplies can be secured when regular supplies are curtailed or when demand is high.

2. Gas producers and distributors can manage so as to keep with market demand.

3. Underground gas storage is cost effective since it minimizes large pipelines needed for storage.

4. Gas storage also helps in creation of a gas spot market to cater for differentials in gas prices $^{15}$.

\subsection{Optimization of the Storage}

A structure's geological and geometrical characteristics play a commanding role in determining the principal performances of an underground storage facility and therefore, sound knowledge of the structural form and heterogeneity of the reservoir helps optimize development and operation $^{(16,17)}$. 


\subsubsection{Geological Challenges}

The search for locating the structures capable of storing natural gas requires in depth study of the formation. Geometry parameters like thickness, depth, layering, isopachs, and gas-water contact depths would help. Hydro geological properties such as porosities, permeabilities of different geological units and capillary pressure curves related to storage horizon would be very critical when taking the decision whether the field is suitable for storage purposes ${ }^{18}$. Fluid data such as viscosity and density information as a function of pressures would give a clear idea of how gas is distributed in the facility. The initial assessment of the field would evaluate the total gas that can be stored, peak withdrawal rate, the location and also number of wells required. The use of already producing reservoirs upon depletion would be very helpful because the facility is observed and the geological properties are well understood, the wells and gathering systems can also be utilized.

\subsubsection{Reduction of Cushion Gas Investment}

When natural gas is stored in porous formations there is always certain amount of gas in the reservoir which acts as a cushion and could not be produced along with withdrawn gas. The cushion gas which accounts for large investment representing about 30 to $40 \%$ of the development cost could possibly be replaced by a dissimilar gas typically an inert gas ${ }^{18}$. The significant reduction of cost is seen by this method and gain due to this replacement would depend on the price differential between the inert gas and the natural gas.

The use of inert gas as a cushion would depend on various technological aspects such as gas mixing, geochemical studies and production of cushion gas. The inert gas could be $\mathrm{CO}_{2}$ or $\mathrm{N}_{2}$ depending upon the advantages. The usage of $\mathrm{CO}_{2}$ would also benefit in some tax credits as an environmental challenge. $\mathrm{CO}_{2}$ would have some disadvantages such as corrosion of the equipment and when over pressurized the possibility of explosion cannot be ruled out.

The objective of replacing a less expensive cushion gas in underground storage facilities to reduce the investment cost must be accomplished without affecting the quality of working gas. 
When two miscible gas come into contact the mixing is unavoidable but could be controlled through the technology and the certain strategy like injection of the inert gas on the flanks of storage field so that cushion gas would maintain the pressure and volume without contaminating the working gas. The French natural gas utility, Gaz de france has experience of storing both natural and non pipeline quality gas in a storage field ${ }^{19}$. The first experience was using the manufactured gas as a cushion gas and after it was observed no contamination in the quality of the working gas. The pilot projects success encouraged the team to replace part of the cushion gas with inert nitrogen. The Gas Research Institute in United States initiated a research effort at Institute of Gas Technology to develop an approach to use inert gas as cushion in the year 1986. The analysis indicated that nitrogen can be used as a substitute to replace the cushion gas and a measurable percentage of nitrogen is withdrawn in working gas. Upon completion of the study citizens gas and coke utility offered Simpson chapel storage filed for full scale field test of inert gas use and after the study the institute revealed that the Simpson chapel field is not suitable because of the fracture system and would result in mixing contaminating the quality of gas to a great extent. The objective of this study is to see the effect of mixing and the concentration of the nitrogen in withdrawn gas on a long-term scenario.

\subsection{Factors influencing Mixing between Inert Cushion and Natural Gas}

Apart from economic reasons, the feasibility of using an inert gas as cushion in gas storage reservoir is dependent upon the rate of mixing of the cushion and working gases. The four governing mechanisms that occur during storage are (1) Molecular diffusion-dispersion transport, (2) Mutual displacement efficiency of the cushion and the working gases (convective transport), (3) Effect of variable permeability, allowing one gas to move faster than another.

\subsubsection{Molecular Diffusion-Dispersion Transport}

Mixing is conventionally introduced by process of diffusion and dispersion. Molecular diffusion is a physical phenomena related to molecular agitation. "Brownian movement" creates a particle displacement in all directions. This results in a transport of particles from the higher concentration zones to the lower ones. Molecular diffusion is isotropic and occurs even without 
any fluid displacement ${ }^{20}$. Its action is very limited in porous media and it acts only inside the fluid gas phase. Diffusion is a result of random motion of the gas molecules. The theory of molecular diffusion was first developed on a quantitative basis by Fick's law. The equation of diffusion in homogeneous substances is based on the hypothesis that the rate of transfer of a diffusing substance through unit area of cross section is proportional to the concentration gradient measured at right angles to the cross section ${ }^{21}$.

$$
F=-D \frac{d C}{d X}---------(1)
$$

Where

F - Rate of transfer per unit area of section

D - Coefficient of diffusion, dependent upon substances considered

C - Concentration of diffusing substance

$\mathrm{X}$ - Distance measured at right angles to section

Above equation (1) is Fick's first law of diffusion from which his second law is derived,

$$
\frac{d C}{d t}=D \frac{d^{2} C}{d X^{2}}---------(2)
$$

Where

$\mathrm{C}$ - Concentration of diffusing substance at time $\mathrm{t}$

D - Coefficient of diffusion, dependent upon substances considered

The magnitude of the diffusion depends on the formation factor of the reservoir, the porosity and the gas saturation. Due to the pore geometry and fluid saturation of Underground formations, the diffusion coefficient as determined by classical methods has to be altered to an effective value ${ }^{21}$. For practical considerations, in a completely gas saturated formation, the effective diffusion coefficient can be expressed as

$$
D_{e}=\frac{D}{\tau}-----------(3)
$$

Where 
$\mathrm{De}=$ Effective coefficient of diffusion

$\mathrm{D}=$ Standard coefficient of diffusion at temperature $\mathrm{T}$ and pressure $\mathrm{P}$

$\tau=$ Tortuosity factor of reservoir formation

The value of tortuosity gives an indication of how the structure of the porous medium restricts the flow of liquids or gases through the material ${ }^{22}$.

Dispersion is used to cover a variety of physical phenomena ${ }^{23}$. Dispersion is a mechanical mixing due to velocity differences within tiny capillaries. The scale of macroscopic dispersion is related to length of heterogeneities. It is accepted that on a field scale typically hundreds of meters dispersion is dominant. At the reservoir's scale, layering effects, clay lenses, fractures and other kind of macro geological heterogeneity create different velocities and consequently are responsible for mixing.

\subsubsection{Convective Transport}

Convective transport is due to physical movement of the mixture. At a macroscopic level the convective transport is described by Darcy's law which states that volumetric flow rate is proportional to pressure gradient ${ }^{24}$. Convective transport results from the following phenomena Gravity, Capillarity and Viscosity.

These three phenomena may contribute to mixing between two different gases. The difference of density between two gases may cause vertical movements that mix two gases. The vertical movement caused by gravity interests one to introduce an inert gas at the bottom of a gas storage reservoir. The hysteresis of capillarity phenomena is responsible for a large part of the mixing problems with convective transport.

The viscosity effect on mixing ${ }^{20}$ is the well known effect and it is defined by the mobility ratio of the gases. It has been found by numerical simulations that an unfavorable viscosity ratio in 
enhanced oil recovery by gas sweeping, sometimes causes poor efficiency because of excessive mixing.

\subsection{Previous Work}

The study of replacement of cushion gas by nitrogen was studied earlier by Balaji Srinivasan under the research guidance of Dr. K. Aminian ${ }^{25}$. The study focused on vertical and peripheral placement of cushion gas by nitrogen using the CMG reservoir software. The simulations were conducted for Injection and Withdrawal cycles to see the impact of reservoir properties on mixing. The reservoir was assumed to contain nitrogen. The simulations were conducted to perform only 2 withdrawal cycles. The current study would focus on extending the withdrawal cycles to have a detailed observation of mixing effect and also injecting nitrogen in to reservoir.

\subsection{Reservoir Modeling Software}

Reservoir simulation model is a cost effective engineering and management tool that helps you make the most of the exploration and production investments. Computer Modeling Group $(\mathrm{CMG})$ is reservoir simulation software that assists oil and gas companies to determine reservoir capacities and maximize potential recovery. GEM is an efficient equation of state compositional simulator which can simulate mechanisms of miscible injection process such as vaporization and swelling of oil, condensation of gas, viscosity and interfacial tension reduction ${ }^{26}$. Gem utilizes either Peng Robinson or the Soave Redlich kwong equation of state to predict the phase equilibrium compositions. Gem uses grid builder for interpreting the reservoir definition keywords used to describe complex reservoir ${ }^{26}$.

\subsubsection{Input Output control}

The I/O section allows users in naming conventions as titles and case ID in organizing the simulation runs. The output of the simulation can be formatted according to the user's choice if specific parameters need to be observed in particular intervals of time period. This section also helps in managing the error and interrupt actions to stop and give information. 


\subsubsection{Description of Reservoir}

The reservoir can be built in the desired form such as Cartesian, Cylindrical or may be imported using the grid module. The number of blocks, size and shape of the block can be defined by the user in a three dimensional way signifying $\mathrm{i}, \mathrm{j}$, and $\mathrm{k}$ directions. The input data including the information of each formation top of the reservoir, thickness of the layers, reservoir depth, and fracture dimension, permeability of fracture, matrix and related parameters of the reservoir are loaded to the model. The model defined templates are present if wanted to create a quick model such as coal bed methane or aquifer models.

\subsubsection{Components}

In this part all the thermodynamic properties of fluids such as reservoir temperature, PVT table for gas, fluid densities, water and gas compressibility, viscosity and all other properties are be added to the model. Equation of state can be chosen to predict the phase equilibrium compositions. The model can also be generated with win prop if desired by a user on specific recommendations or readily available model such as quick CBM setup can be used.

\subsubsection{Rock Fluid Properties}

This section contains all the data related to different rock types and their characteristics like capillary pressure, saturation and relative permeability curves. New rock types can be added or deleted. Relative permeability tables, hysteresis modeling can be defined.

\subsubsection{Initial Conditions}

This section allows one to enter information regarding the initial state of the reservoir. Additional information that can be entered includes calculation methods, gas plant tables, and well separators. Initial reservoir pressure, datum depth and gas water contact are assigned to the model.

\subsubsection{Numerical Control Methods}

The terms related to the control of numerical calculation and execution time were presented in this model. Default values are given in this section and user can override the values for ones 
comfort like the time step size and variation of a parameter on time step. The appropriate method of solution can be used by selecting from the available solvers such as Newton solution method, linear solver or parallel solver.

\subsubsection{Well Data}

The well and recurrent data section is where one defines wells and groups, well locations and type, sets production and injection constraints, and defines well completions and other properties as a function of time. Wells created could be shut-in or open at the user specified times and well trajectories are also guided in the desired layers or imported from available source. Two or more wells can be grouped to achieve the desired production. 


\section{CHAPTER 3}

\section{METHODOLOGY}

The objective of this research is to study the impact of mixing in an underground storage reservoir when a part of cushion gas is replaced by nitrogen. The following steps were followed this study.

1. Three base models of the storage reservoirs were developed using reservoir simulator for different scenarios including peripheral placement of nitrogen and injection of nitrogen in several stages in different size reservoirs.

2. Simulations runs were conducted for seven Injection/Withdrawal cycles by varying percentage of nitrogen cushion, pressure, porosity, and permeability of the reservoir to study the impact of mixing in detail.

3. Mole percentages of nitrogen in the withdrawn gas were calculated at the end of each day during the withdrawal cycles.

4. A graphical plot of percentage nitrogen in withdrawn gas as a function of time for each withdrawal cycle were plotted to observe the mixing trend.

\subsection{Development of Base Models}

Base models were developed using CMG Grid builder. A square storage reservoir of area 40 acres is developed with 3 vertical layers each of $20 \mathrm{ft}$ thick.

\subsubsection{Reservoir Grid}

The CMG Grid builder is used to develop a reservoir grid system. In this study the reservoirs used are developed using the Cartesian grid system. The top view of a grid system is shown in Figure 2. The grid consists of a square area 40 acres with 26 blocks of size $50 \mathrm{ft} \times 50 \mathrm{ft}$ 
on each side. Each side of reservoir is $1300 \mathrm{ft}$.The model is $60 \mathrm{ft}$ thick with 3 layers each of $20 \mathrm{ft}$ thickness. The reservoir is assumed to be $2000 \mathrm{ft}$ deep. The dimensions of the grid system and the grid top of each layer are illustrated in Figure 3.

Grid Top (ft) 2001-01-01 Klayer: 1

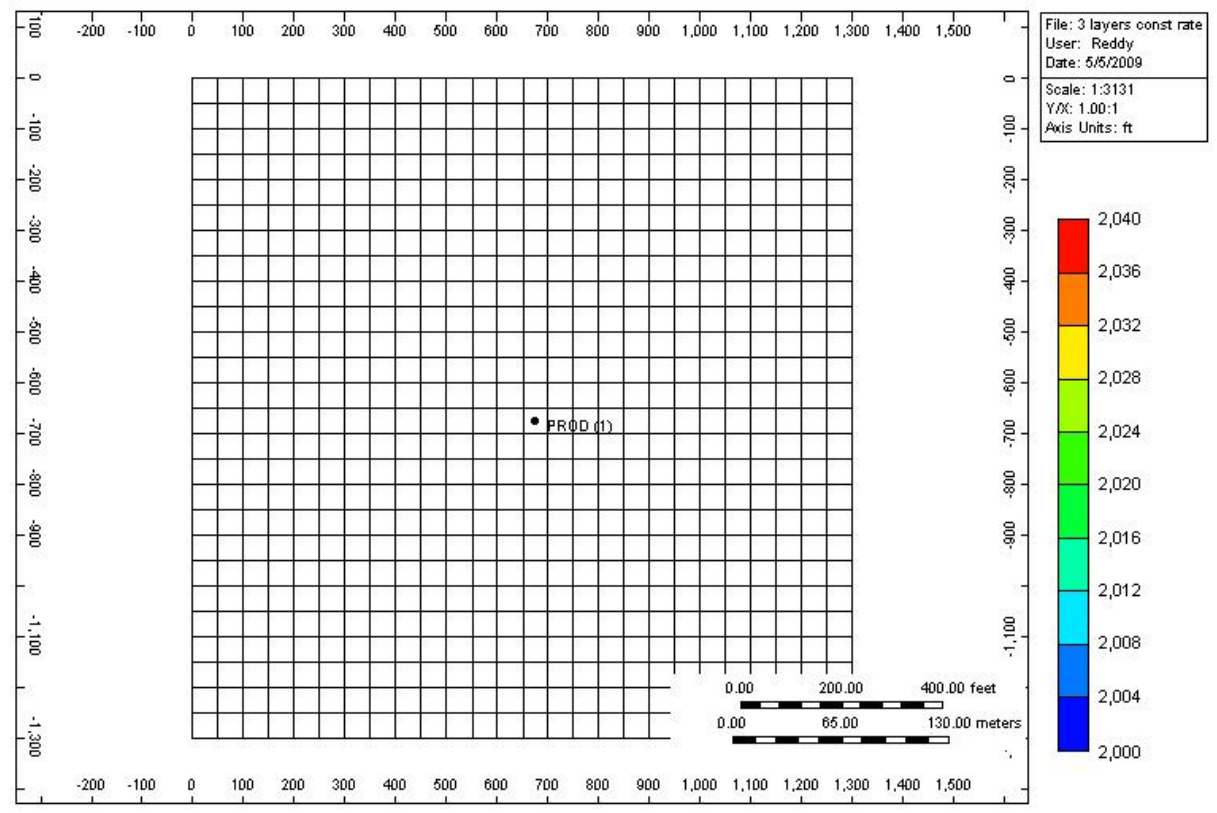

Figure 2 -2D Arial view of the Cartesian grid system

Grid Top (ft) 2001-01-01
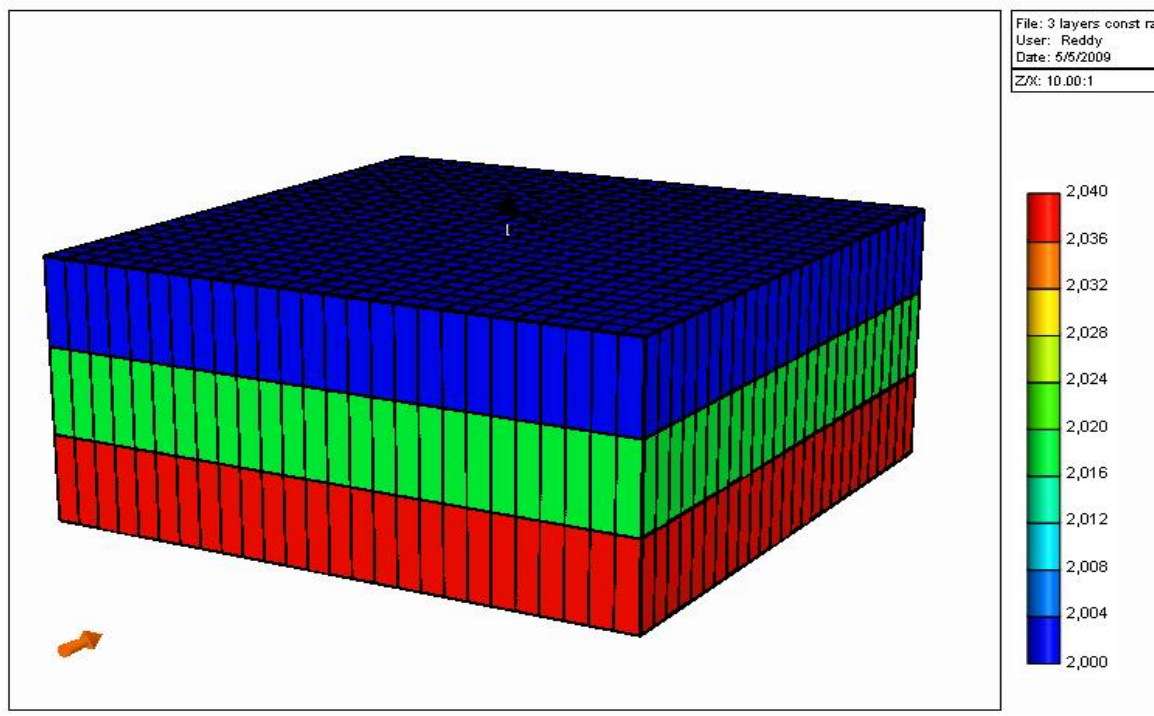

Figure 3 -Grid top of layers 


\subsection{Peripheral Placement of Nitrogen}

The nitrogen was assumed to be present uniformly in the periphery of the model at the start of simulation. The volume of nitrogen present in 10 percent of total reservoir volume. This was achieved by placing $70 \%$ nitrogen in the outer most blocks which is $10 \%$ of total volume of the reservoir. Figure 4 shows the uniform distribution of nitrogen, the scale represents the composition of nitrogen in the reservoir. The reservoir is assumed to contain only methane and nitrogen, water is considered as immobile. The horizontal permeability is $100 \mathrm{md}$ and vertical permeability is 10 md. In this study, all the cases simulated assume a ratio of 10 to 1 between horizontal and vertical permeability. The porosity was assumed to be $20 \%$ and temperature of $120^{\circ} \mathrm{F}$. Initial reservoir pressure is 1000 psia.

Global Composition(N2) - Fracture 2001-01-01

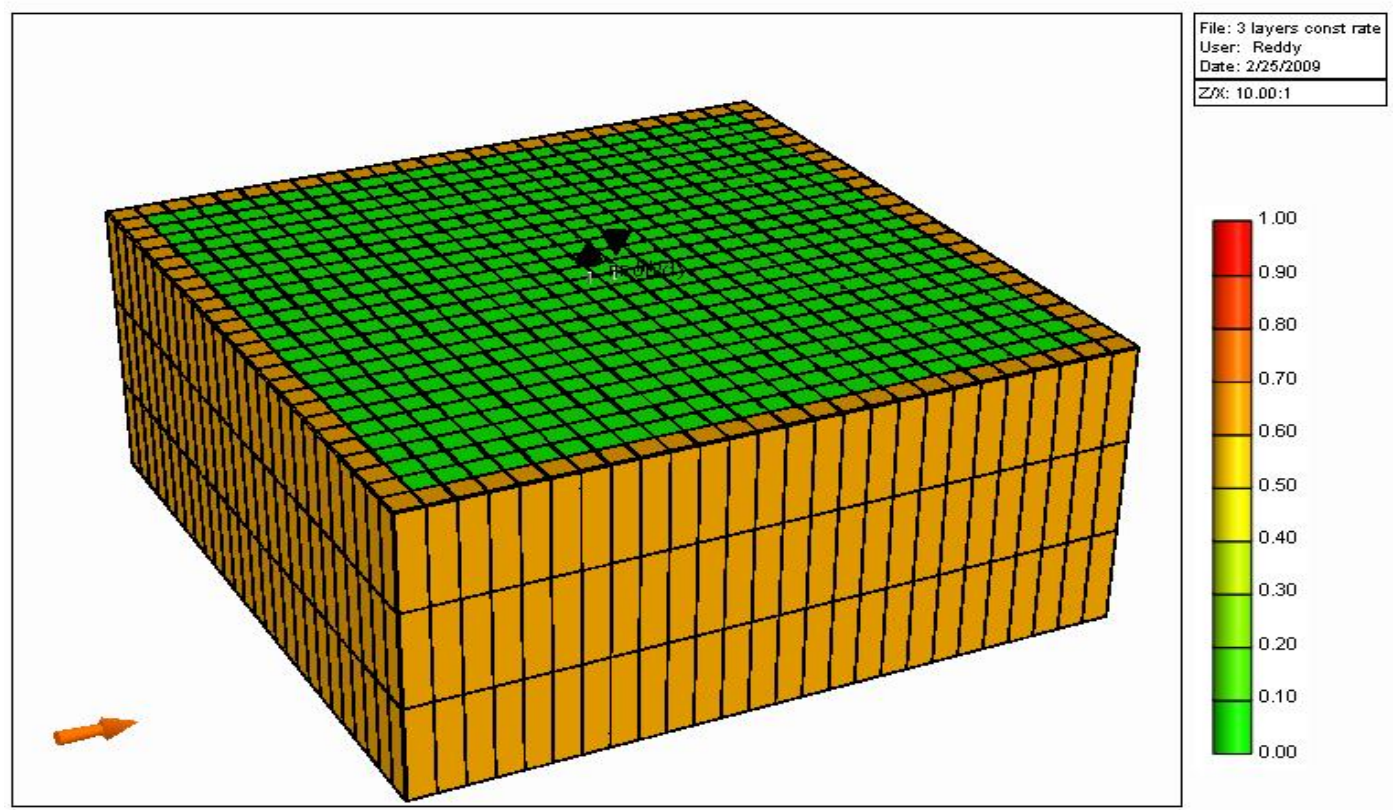

Figure 4 -Nitrogen distributed in outer layer $10 \%$ by Volume

An Injection/Withdrawal well was simulated by two wells at the center of model as shown in Figure 4. Two set of constraints were simulated including constant rate and constant bottom hole pressure. The rate is adjusted such that during each cycle $50 \%$ of total gas is produced over 4 
months. A shut-in period of 1 month is observed after every withdrawal cycle. The natural gas is injected for a period of 6 months in to the reservoir at a constant rate such that volume of injected gas is equal to volume of the withdrawn gas. This withdrawal for 4 months and injection for 6 months followed by shut-in period of 1 month after injection and production is termed as one cycle of 12 months long. Total of 7 cycles were simulated.

Similarly as shown in Figure 5, the nitrogen is distributed in the two outer most blocks such that volume of nitrogen is $20 \%$ of total volume of reservoir. The outer most blocks contain $100 \%$ and $50 \%$ nitrogen by volume which is equivalent to $20 \%$ of total volume of reservoir. Methane composition in the reservoir is represented by a scale as shown in the Figure 5. The gas is withdrawn for 7 cycles. Reservoir parameters such as permeability, porosity, temperature, and pressure are varied to study their impact on mixing. The Tables 1 and 2 show the distribution of components in the reservoir and their withdrawal rates.

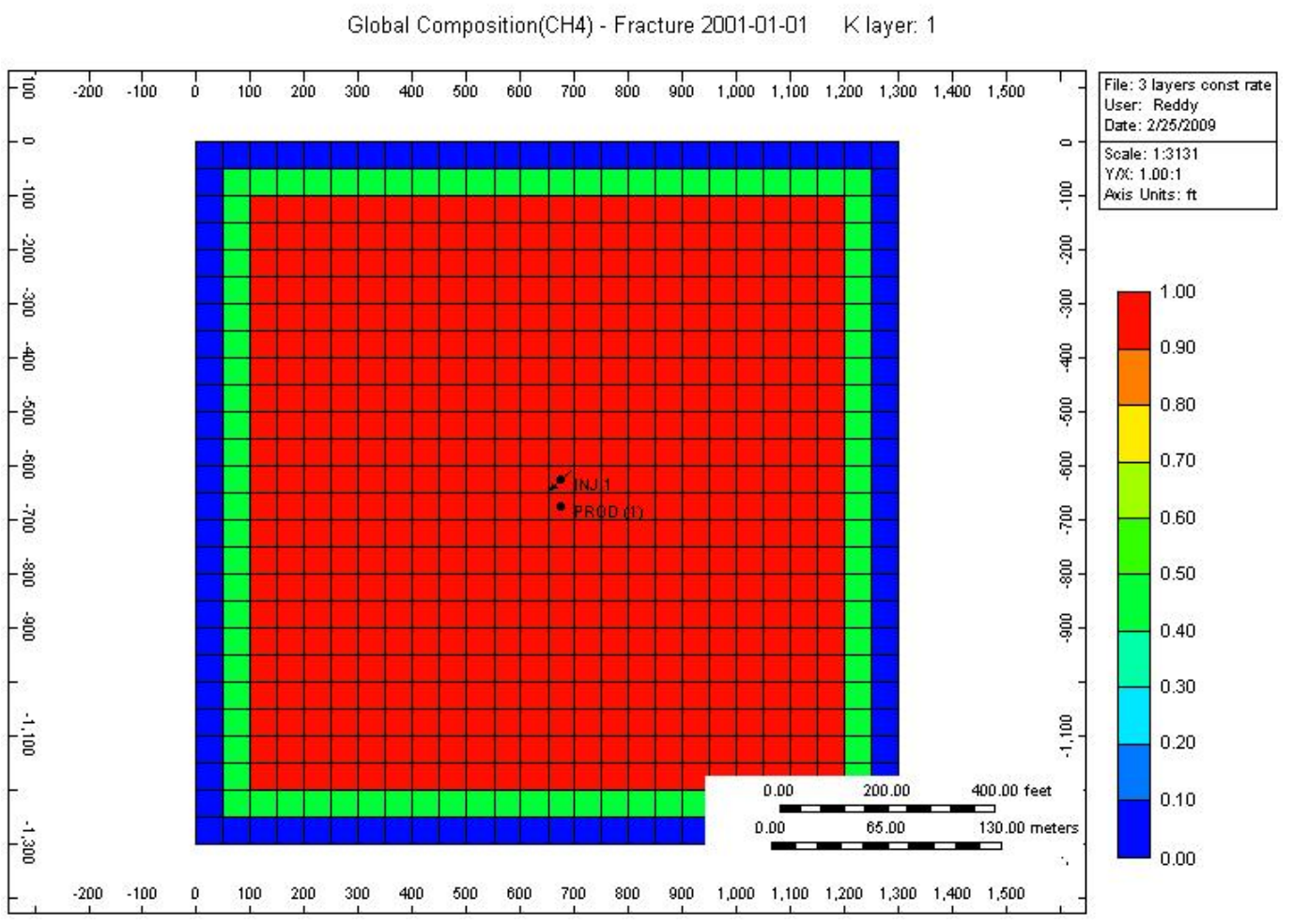

Figure 5 -Nitrogen distributed in two outer most layers $20 \%$ by Volume 
Table 1 - Distribution of Components in Peripheral Nitrogen Placement Models

\begin{tabular}{|c|c|c|}
\hline Component & Volume & Distribution \\
\hline Working Gas (methane) & $50 \%$ & \\
\hline $\begin{array}{c}\text { Cushion Gas(Nitrogen \& } \\
\text { methane) }\end{array}$ & $10 \%+40 \%$ & $\begin{array}{c}\text { Nitrogen is distributed along the sides in the outer } \\
\text { most blocks }\end{array}$ \\
\hline $\begin{array}{c}\text { Cushion Gas(Nitrogen \& } \\
\text { methane) }\end{array}$ & $20 \%+30 \%$ & $\begin{array}{c}\text { Nitrogen is distributed along the sides in } 2 \text { outer } \\
\text { most blocks }\end{array}$ \\
\hline
\end{tabular}

Table 2 - Component distribution and withdrawal rate in Peripheral Nitrogen Placement Models

\begin{tabular}{|c|c|c|c|c|c|}
\hline $\begin{array}{c}\text { Cushion gas } \\
\text { replaced }\end{array}$ & Pressure & Working gas & Methane & Nitrogen & Withdrawal rate \\
\hline $\begin{array}{c}\text { \%(total } \\
\text { volume) }\end{array}$ & Psia & Scf & g-moles & g-moles & mmcfd \\
\hline 10 & 1000 & $5.32 \times 10^{8}$ & $9.5 \times 10^{8}$ & $1.1 \times 10^{8}$ & 4.43 \\
\hline 20 & 1000 & $5.32 \times 10^{8}$ & $8.48 \times 10^{8}$ & $2.12 \times 10^{8}$ & 4.43 \\
\hline
\end{tabular}

\subsection{Injection of Nitrogen}

The peripheral placement of nitrogen as simulated in previous case is practically impossible to achieve. Therefore an injector well is used to introduce the Nitrogen in to storage reservoir. The grid block consists of the same dimensions as the base model. There are 2 wells in this case an Injection/Withdrawal well located at the center for methane production and injection, and a nitrogen injection well located on the corner of the reservoir. The simulation runs were conducted but the observations indicated that considerable amount of nitrogen was present in withdrawn gas because of the close proximity of nitrogen injector and methane producer. Therefore an alternate well pattern was considered. 
The new model designed with diagonal placement of nitrogen injector on one corner and the methane Injector/Withdrawal well on other corner as shown in Figure 6. The scale in the figure represents the nitrogen composition in the reservoir. 7 Injection/Withdrawal cycles were simulated such that total nitrogen injected in to the reservoir does not exceed $10 \%$ of the total volume. The dimensions of the models were same as base model, square in shape of area 40 acres with a block width of $50 \mathrm{ft}$ and 26 blocks on each side. The initial pressure was assumed to be 1000 psia.

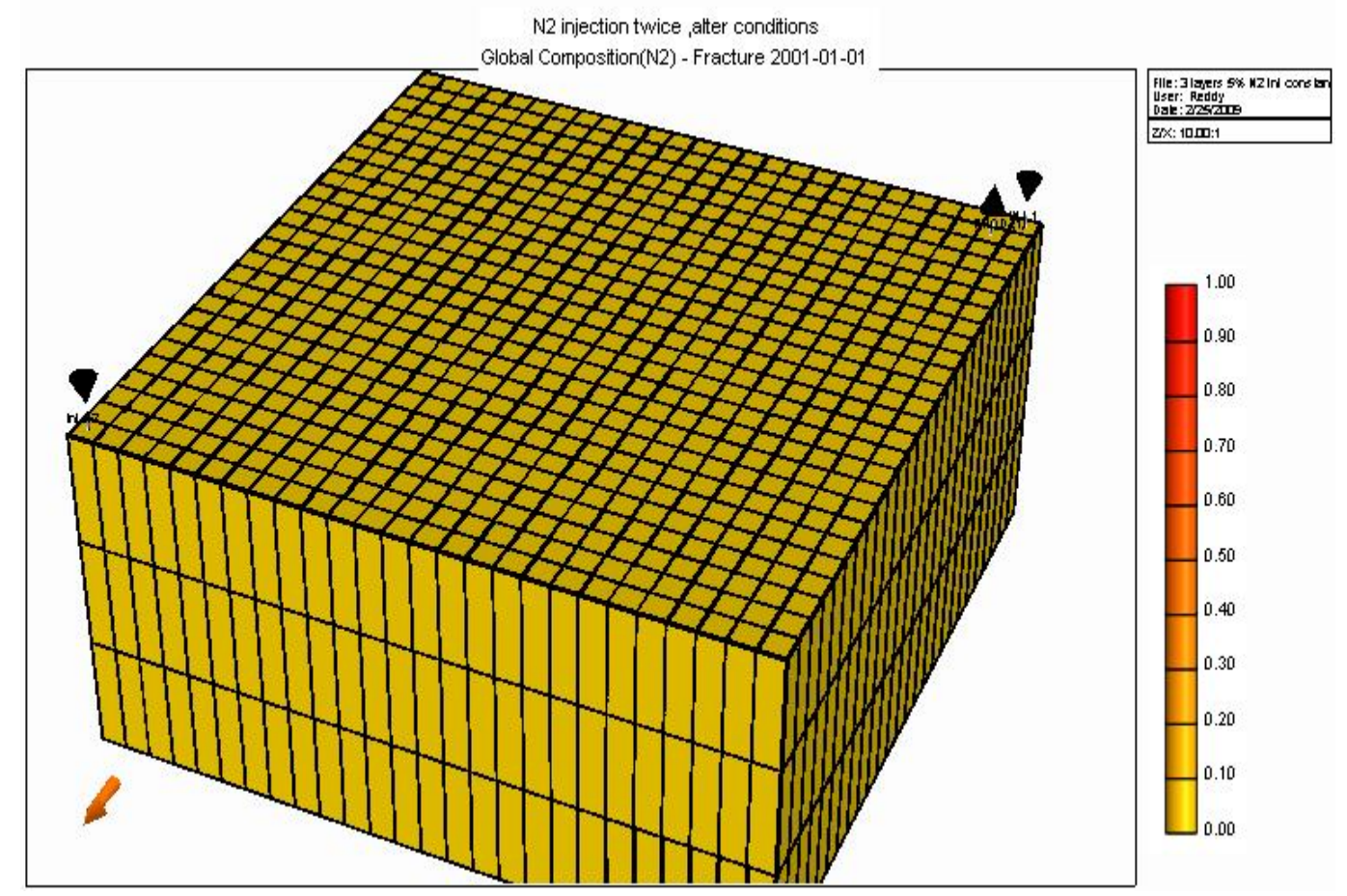

Figure 6- The diagonal well placement of nitrogen injector and methane producer.

Two cases were considered in injecting nitrogen with Case 1 as $10 \%$ injection of total volume of reservoir and Case 2 as $20 \%$ injection of total volume of storage reservoir. The injection of nitrogen occurs in 2 stages so as to minimize mixing. The simultaneous injection of nitrogen and methane is modeled so that the movement of nitrogen towards methane well is slowed down. Table 3 shows the division of cases on percentage of nitrogen injected. 
Table 3 - Injection of Nitrogen - Division of cases based on amount of nitrogen injected

\begin{tabular}{|l|c|l|c|c|c|}
\hline Model & $\begin{array}{c}\text { Working } \\
\text { gas }\end{array}$ & Methane & $\begin{array}{c}\text { Withdrawal } \\
\text { rate }\end{array}$ & Nitrogen & Injection stages \\
\hline & g-moles & g-moles & mmcfd & & \\
\hline Case 1 & $1.25 \times 10^{9}$ & $2.52 \times 10^{9}$ & 10.46 & $10 \%$ & Injected in two stages of $5 \%$ \\
each
\end{tabular}

\subsubsection{Injection Withdrawal Cycles}

The reservoir initially contains $100 \%$ methane. $50 \%$ of the methane is produced in 4 months and the well is shut-in for a period of 1 month. The methane injector and nitrogen injector wells are then opened and respective gases were injected in to the reservoir for 6 months. Injected volume of gas is equal to the produced gas; the volumes of the methane and nitrogen injected are $45 \%$ and $5 \%$ respectively. The injector wells are then shut-in for a period of 1 month. This completes one cycle of the simulated 7 cycles. This process of injection and withdrawal are repeated but nitrogen injection does not occur in the second cycle. $5 \%$ of nitrogen is injected in the reservoir simultaneously with methane injection in the third cycle. At this point the total amount of injected $\mathrm{N}_{2}$ in to the reservoir is $10 \%$ of total volume of reservoir. The nitrogen can also be injected in two supplements of $10 \%$ of volume which is equivalent to $20 \%$ of the total volume. After the completion of seven Injection/Withdrawal cycles the concentration of nitrogen in the withdrawn gas in each cycle is calculated and compared. Table 4 shows the time of open and shut in periods along with the percentage of nitrogen injected of the total volume. 
Table 4 - Withdrawal and Injection scenarios

\begin{tabular}{|c|c|c|c|c|c|}
\hline $\begin{array}{c}\text { Cycle } \\
\text { (each cycle is } \\
\mathbf{1 2} \text { months) }\end{array}$ & $\begin{array}{c}\text { Working gas } \\
\text { produced } \\
\text { for } \mathbf{4} \text { moths }\end{array}$ & $\begin{array}{c}\text { Shut-in } \\
\text { period in } \\
\text { months }\end{array}$ & $\begin{array}{c}\text { Methane } \\
\text { Injected for } \\
\mathbf{6} \text { months }\end{array}$ & $\mathbf{N}_{2}$ injected & $\begin{array}{c}\text { Shut-in } \\
\text { period in } \\
\text { months }\end{array}$ \\
\hline 1 & $50 \%$ & 1 & $45 \%$ & $5 \%$ (6months) & 1 \\
\hline 2 & $50 \%$ & 1 & $50 \%$ & Shut-in & 1 \\
\hline 3 & $50 \%$ & 1 & $45 \%$ & $5 \%$ & 1 \\
\hline 4 & $50 \%$ & 1 & $50 \%$ & Shut-in & 1 \\
\hline 5 & $50 \%$ & 1 & $50 \%$ & Shut-in & 1 \\
\hline 6 & $50 \%$ & 1 & $50 \%$ & Shut-in & 1 \\
\hline 7 & $50 \%$ & 1 & $50 \%$ & Shut-in & 1 \\
\hline
\end{tabular}

Simulations were conducted by varying pressure, permeability, porosity, temperature and percentages of nitrogen to study the impact on mixing. The Tables 5 through 9 show the composition and distribution of components by percentage of total volume and the rate at which methane gas was withdrawn.

Table 5 - Case 1 - Distribution of components and withdrawal rate at different pressures

\begin{tabular}{|c|c|c|c|c|}
\hline Pressure & Working gas & Methane & Nitrogen & Withdrawal rate \\
\hline Psia & g-moles & g-moles & g-moles & Mmcfd \\
\hline 1000 & $1.25 \times 10^{9}$ & $2.27 \times 10^{9}$ & $2.52 \times 10^{8}$ & 10.46 \\
\hline 2000 & $2.03 \times 10^{9}$ & $3.66 \times 10^{9}$ & $4.07 \times 10^{8}$ & 16.95 \\
\hline
\end{tabular}


Table 6 - Case 2 - Distribution of components and withdrawal rate at different pressures

\begin{tabular}{|c|c|c|c|c|}
\hline Pressure & Working gas & Methane & Nitrogen & Withdrawal rate \\
\hline Psia & g-moles & g-moles & g-moles & Mmcfd \\
\hline 1000 & $1.25 \times 10^{9}$ & $2.02 \times 10^{9}$ & $5.04 \times 10^{8}$ & 10.46 \\
\hline 2000 & $2.03 \times 10^{9}$ & $3.26 \times 10^{9}$ & $8.14 \times 10^{8}$ & 16.95 \\
\hline
\end{tabular}

Table 7 shows the distribution of working gas (methane) and cushion gas (methane and nitrogen) present at different permeability. The nitrogen cushion injected in to the reservoir is $10 \%$ of the total volume of reservoir. The gas is withdrawn at the rate of $10.46 \mathrm{mmcfd}$ for 120 days.

Table 7 - Case 1 - Distribution of components and withdrawal rate at different permeability

\begin{tabular}{|c|c|c|c|c|}
\hline Permeability & Working gas & Methane & Nitrogen & Withdrawal rate \\
\hline (i,j,k) md & g-moles & g-moles & g-moles & Mmcfd \\
\hline $100,100,10$ & & & & \\
\cline { 1 - 2 } 200,20020 & \multirow{2}{*}{$1.25 \times 10^{9}$} & $2.27 \times 10^{9}$ & $2.52 \times 10^{8}$ & 10.46 \\
\hline 300,30030 & & & & \\
\hline
\end{tabular}

Table 8 shows the distribution of components and the withdrawal rate for varying porosity when $10 \%$ nitrogen of total volume is injected in to the reservoir. Similarly Table 9 show the distribution of components and withdrawal rates when $20 \%$ nitrogen of total volume is injected in to reservoir. 
Table 8 - Case 1 - Distribution of components and withdrawal rate for different porosity

\begin{tabular}{|c|c|c|c|c|}
\hline Porosity & Working gas & Methane & Nitrogen & Withdrawal rate \\
\hline \% & g-moles & g-moles & g-moles & Mmcfd \\
\hline 10 & $6.27 \times 10^{8}$ & $1.12 \times 10^{9}$ & $1.25 \times 10^{8}$ & 5.20 \\
\hline 20 & $1.25 \times 10^{9}$ & $2.27 \times 10^{9}$ & $2.52 \times 10^{8}$ & 10.46 \\
\hline 30 & $1.88 \times 10^{9}$ & $3.38 \times 10^{9}$ & $3.76 \times 10^{8}$ & 15.7 \\
\hline
\end{tabular}

Table 9 - Case 2 - Distribution of components and withdrawal rate for different porosity

\begin{tabular}{|c|c|c|c|c|}
\hline Porosity & Working gas & Methane & Nitrogen & Withdrawal rate \\
\hline$\%$ & g-moles & g-moles & g-moles & Mmcfd \\
\hline 10 & $6.27 \times 10^{\wedge} 8$ & $1.00 \times 10^{9}$ & $2.50 \times 10^{8}$ & 5.20 \\
\hline 20 & $1.25 \times 10^{9}$ & $2.02 \times 10^{9}$ & $5.04 \times 10^{8}$ & 10.46 \\
\hline 30 & $1.88 \times 10^{9}$ & $3.01 \times 10^{9}$ & $7.52 \times 10^{8}$ & 15.7 \\
\hline
\end{tabular}

\subsection{Injection of Nitrogen in a larger reservoir}

The grid block size is increased to $100 \mathrm{ft} \times 100 \mathrm{ft}$ with 26 blocks on each side and 3 layers in vertical direction. The shape of reservoir is square and area is 160 acres. The steps followed in simulation were same as the previous model. Methane I/W well and Nitrogen Injector were placed diagonally opposite to each other on corners. Seven cycles of Injection/Withdrawal were planned so as to produce and inject $50 \%$ of gas each time by varying the percentages of nitrogen in injection cycles. The main objective in increasing the grid block size was to increase the physical distance between nitrogen injector and the producer well and observe if that has any impact on the mixing. Table 10 shows the distribution of components and withdrawal rates. 
Table 10 - Distribution of components and withdrawal rate at different pressures for model of block size $100 \mathrm{ft} \times 100 \mathrm{ft}$

\begin{tabular}{|c|c|c|c|c|c|}
\hline Cushion gas replaced & Pressure & Working gas & Methane & Nitrogen & Withdrawal rate \\
\hline (total volume)\% & Psia & Scf & g-moles & g-moles & Mmcfd \\
\hline 10 & 1000 & $5.01 \times 10^{9}$ & $9.01 \times 10^{9}$ & $1.00 \times 10^{9}$ & 41.78 \\
\hline 10 & 2000 & $1.06 \times 10^{10}$ & $1.92 \times 10^{10}$ & $2.13 \times 10^{9}$ & 88.60 \\
\hline
\end{tabular}

The grid block size was increased again to $200 \mathrm{ft} \times 200 \mathrm{ft}$ with 26 blocks on each side. The reservoir area increased to 640 acres. The wells were located in the similar fashion as diagonally opposite on corners. With the increase in reservoir area the production of $50 \%$ of methane gas from one producer well was not possible and therefore this simulated model is aborted.

Table 11 - Distribution of components and withdrawal rate for model of block size $200 \mathrm{ft} \times 200 \mathrm{ft}$

\begin{tabular}{|c|c|c|c|c|c|}
\hline $\begin{array}{c}\text { Cushion gas } \\
\text { replaced }\end{array}$ & Pressure & Working gas & Methane & Nitrogen & $\begin{array}{c}\text { Withdrawal } \\
\text { rate }\end{array}$ \\
\hline (total volume)\% & Psia & Scf & g-moles & g-moles & Mmcfd \\
\hline 10 & 1000 & $2.13 \times 10^{10}$ & $3.83 \times 10^{10}$ & $4.26 \times 10^{9}$ & \\
\hline
\end{tabular}

\subsection{Injection of Nitrogen in a rectangular reservoir grid}

The objective of using the rectangular grid is to increase the distance between nitrogen injector and the methane producer. The increase in the block size will increase the distance between the wells but total volume of reservoir is also increased. Hence the results could not be compared. The rectangular grid is developed such that volume of reservoir is same as that of model consisting square area with block size $100 \mathrm{ft} \times 100 \mathrm{ft}$. The rectangular model consists of 52 blocks on the length and 13 blocks on the breadth side with block size is $100 \mathrm{ft} \times 100 \mathrm{ft}$ as shown in Figure 7. The area of the reservoir is 160 acres and consists 3 layers each of $20 \mathrm{ft}$ thickness. The wells are placed diagonally opposite to each other, the distance between the injector and producer 
well is increased by this alignment. The nitrogen is injected in to reservoir simultaneously with methane for a period of 6 months such that total volume of nitrogen injected does not exceed $10 \%$ of total volume of reservoir. Table 12 shows the distribution of components and withdrawal rate in a rectangular grid model.

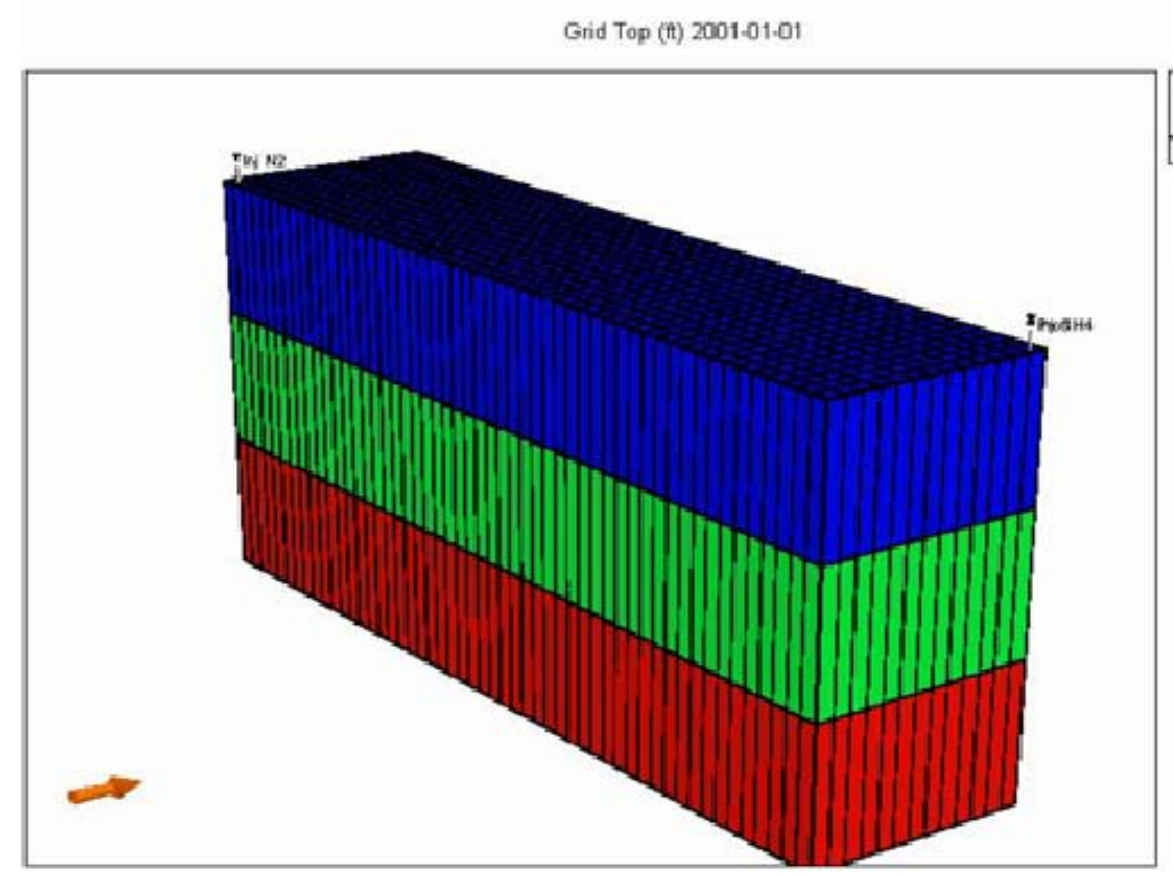

Figure 7- Rectangular reservoir grid

Table 12 - Distribution of components and withdrawal rate for rectangular reservoir grid

\begin{tabular}{|c|c|c|c|c|c|}
\hline $\begin{array}{c}\text { Cushion gas } \\
\text { replaced }\end{array}$ & Pressure & Working gas & Methane & Nitrogen & $\begin{array}{c}\text { Withdrawal } \\
\text { rate }\end{array}$ \\
\hline $\begin{array}{c}\text { (total } \\
\text { tolume)\% }\end{array}$ & Psia & Scf & g-moles & g-moles & mmcfd \\
\hline 10 & 1000 & $4.75 \times 10^{9}$ & $8.56 \times 10^{9}$ & $9.51 \times 10^{8}$ & 39.6 \\
\hline
\end{tabular}




\section{CHAPTER 4}

\section{RESULTS AND DISCUSSIONS}

\subsection{Peripheral Nitrogen Placement Case}

\subsubsection{Effect of mixing on variation in percentage of Nitrogen cushion in reservoir}

The nitrogen cushion gas is placed along the sides of reservoir peripherally with varying concentrations of Nitrogen. The Nitrogen amounts to $10 \%$ and $20 \%$ of total volume for two different scenarios. The Table 13 shows the nitrogen material balance before and after the withdrawal cycle.

Table 13 - Material balance of Nitrogen with different percentages of total volume

\begin{tabular}{|c|c|c|c|}
\hline Nitrogen Cushion & $\begin{array}{c}\text { Nitrogen in reservoir } \\
\text { before withdrawal } \\
\text { cycle }\end{array}$ & $\begin{array}{c}\text { Nitrogen in the reservoir } \\
\text { after withdrawal cycle }\end{array}$ & $\begin{array}{c}\text { Nitrogen in the } \\
\text { withdrawn } \\
\text { gas }\end{array}$ \\
\hline \%(total volume) & g-mol & g-mol & g-mol \\
\hline 10 & $1.06 \times 10^{8}$ & $6.78 \times 10^{7}$ & $3.82 \times 10^{7}$ \\
\hline 20 & $2.12 \times 10^{8}$ & $12.96 \times 10^{7}$ & $8.24 \times 10^{7}$ \\
\hline
\end{tabular}

The graphs from Figures 8 and 9 indicate that mixing is proportional to percentage of nitrogen in the reservoir. In both cases simulated the concentration of nitrogen for 60 days remains very low in the withdrawn gas, but increases rapidly after that time. The results also indicate that nitrogen is being produced along with the natural gas in each withdrawal cycle. The withdrawn gas is observed to contain increased amount of nitrogen in early withdrawal cycles and decline gradually. The reason for this is reduction in amount of nitrogen in the reservoir. 


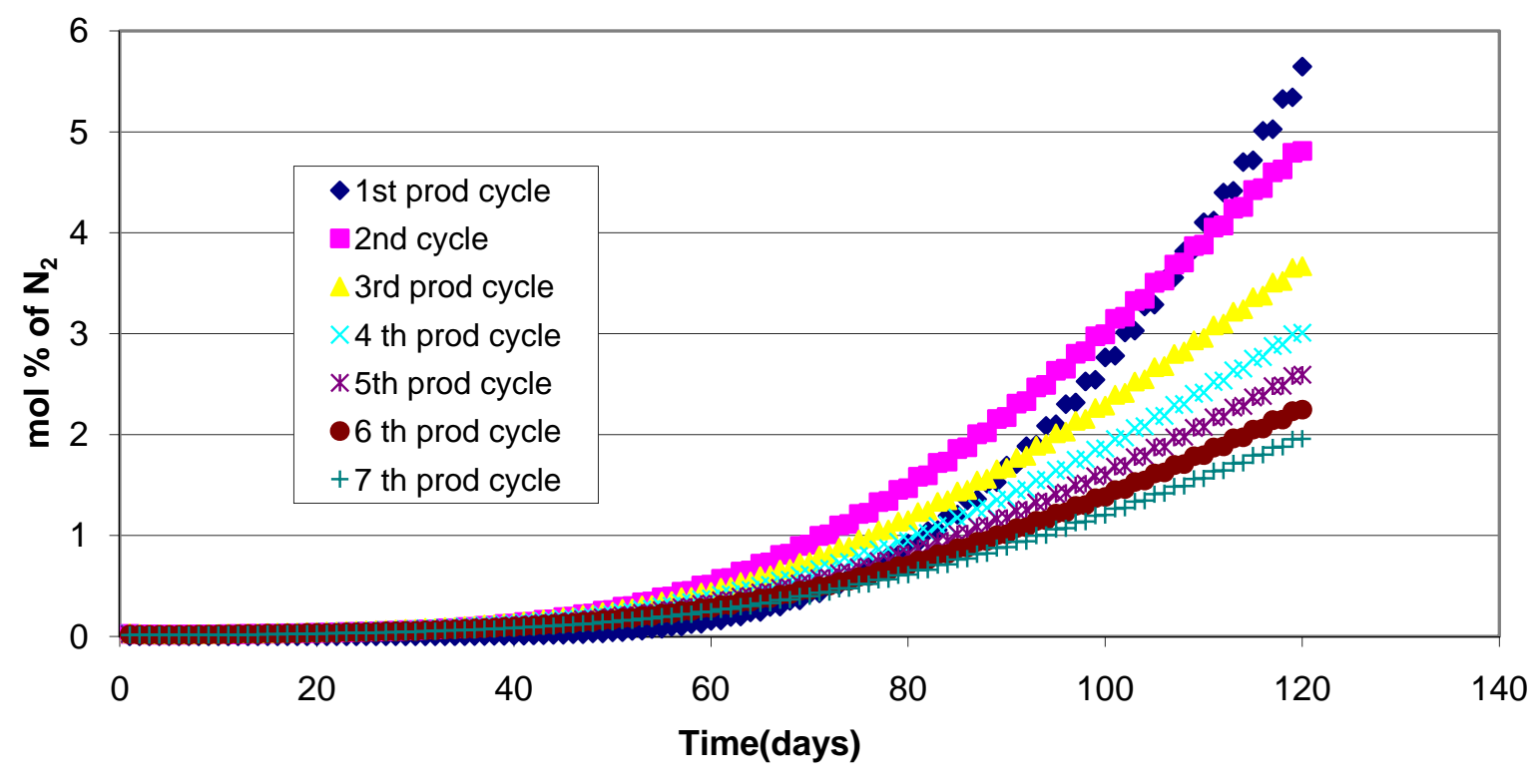

Figure 8- Mole \% of Nitrogen in the Withdrawn Gas $\left(10 \% \mathrm{~N}_{2}\right.$ by Volume $)$

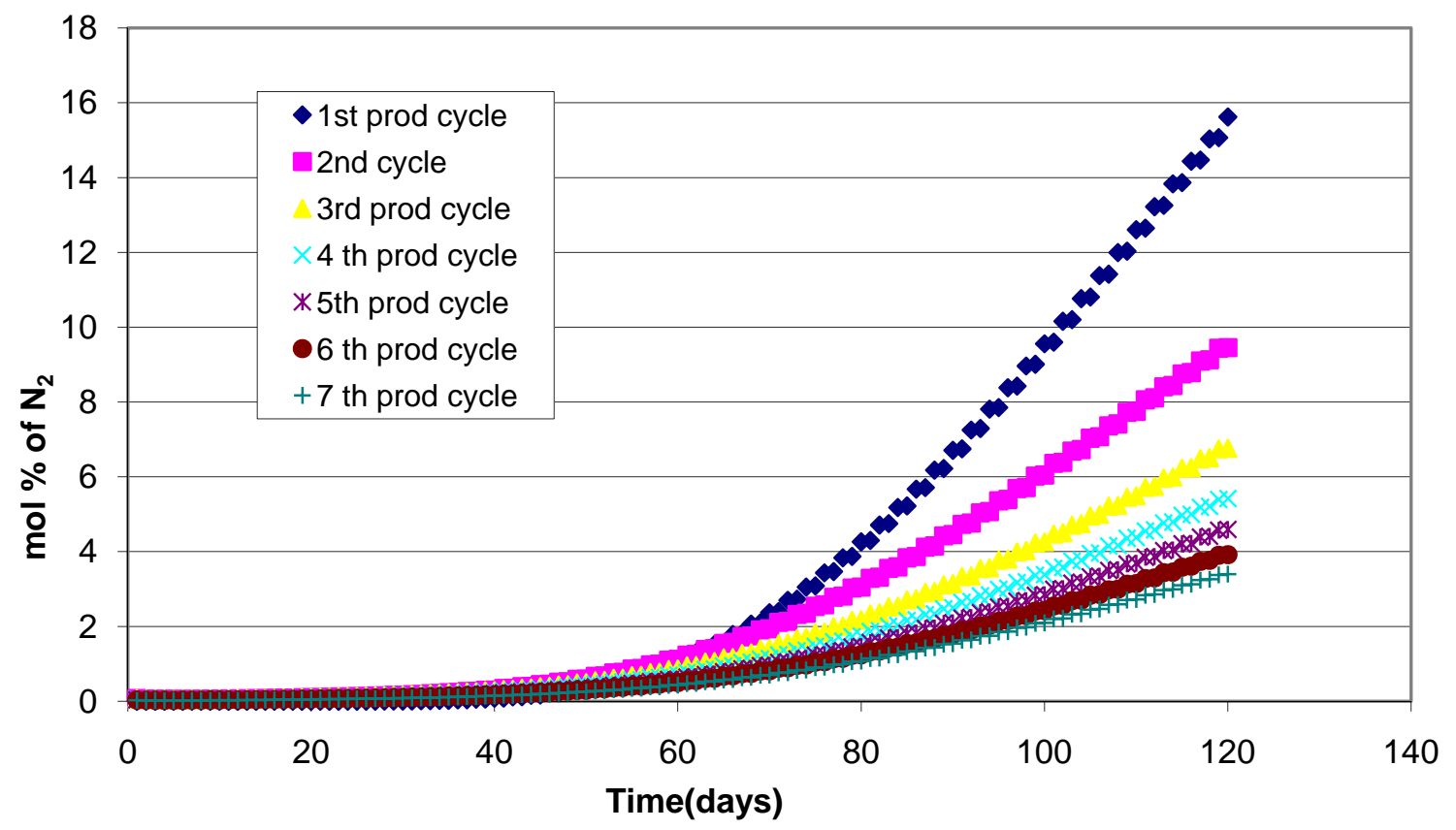

Figure 9- Mole \% of Nitrogen in the Withdrawn Gas $\left(20 \% \mathrm{~N}_{2}\right.$ by Volume) 


\subsection{Injection of Nitrogen through diagonal placement of wells}

The injection of nitrogen from one corner of the reservoir is conducted in two cases as described in the methodology.

The graph from Figure 10 indicates that the amount of mixing is proportional to the percentage of the nitrogen injected in to the reservoir. The $10 \%$ nitrogen use as cushion indicate in Figure 10 that first 3 cycles of withdrawal with nothing or very little concentration of nitrogen in withdrawn gas, from $4^{\text {th }}$ cycle the nitrogen concentration is increasing but eventually at the end of $7^{\text {th }}$ cycle it stabilizes reaching a maximum concentration of $2.4 \%$. The same analysis applies to the $20 \%$ nitrogen used as cushion and reaches a maximum concentration of $6.9 \%$ as shown in Figure11.

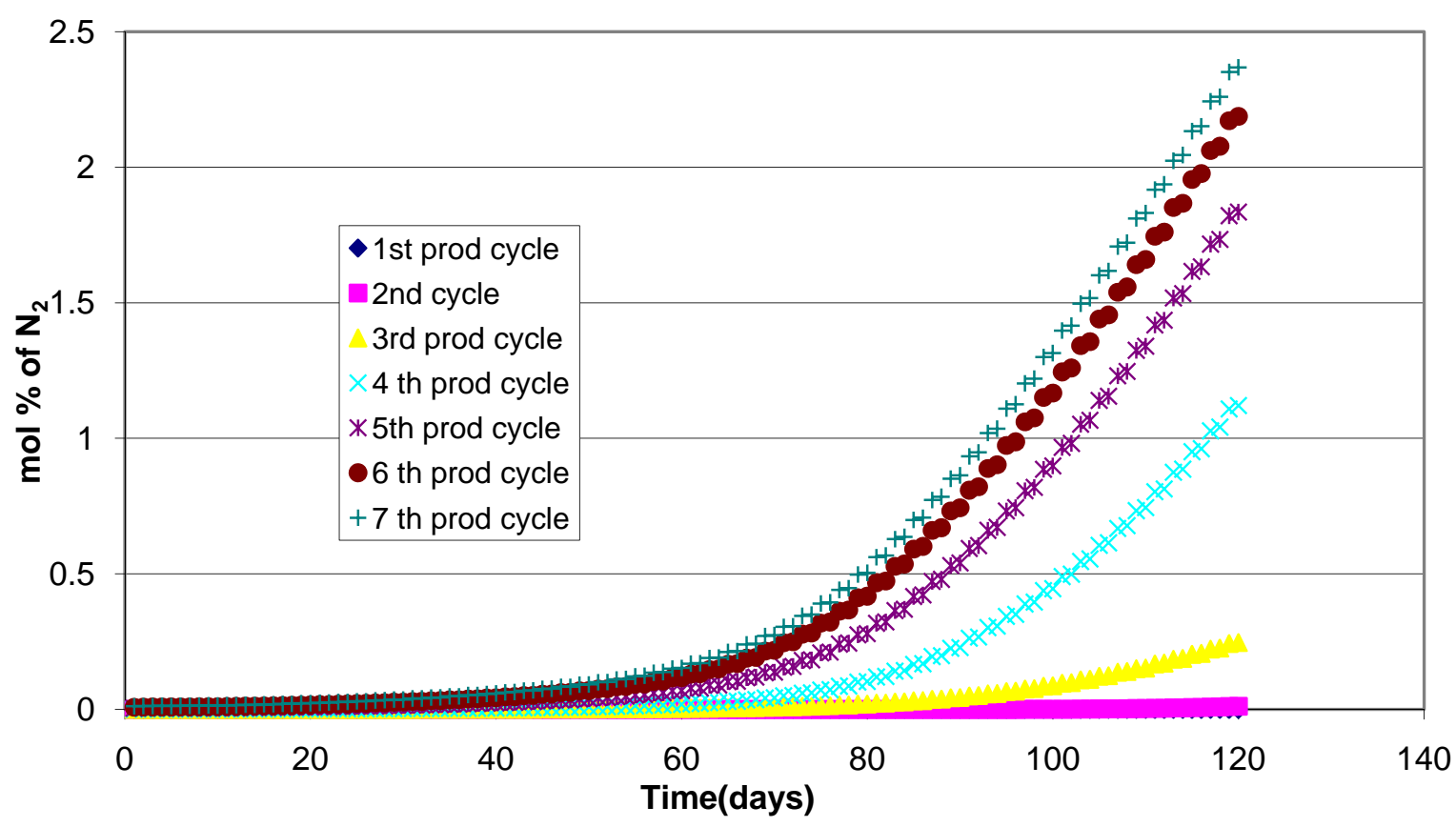

Figure 10- Mole \% of Nitrogen in the Withdrawn Gas (10\% $\mathrm{N}_{2}$ Injected by Volume)

Both case 1 and case 2 from the graphical representation of nitrogen present in withdrawn gas clearly indicate that the injection of nitrogen from corner would yield better result than the 
peripheral placement of nitrogen in the reservoir. The common factor is that both cases behave in a linear fashion until the time period of 80 days and thereafter the increase in the nitrogen concentration is observed, this could be understood as when the reservoir was allowed for long periods of withdrawal the nitrogen starts diffusing towards the well bore. The concentration of nitrogen in withdrawn gas shows that $20 \%$ replacement of total volume by nitrogen is not advisable.

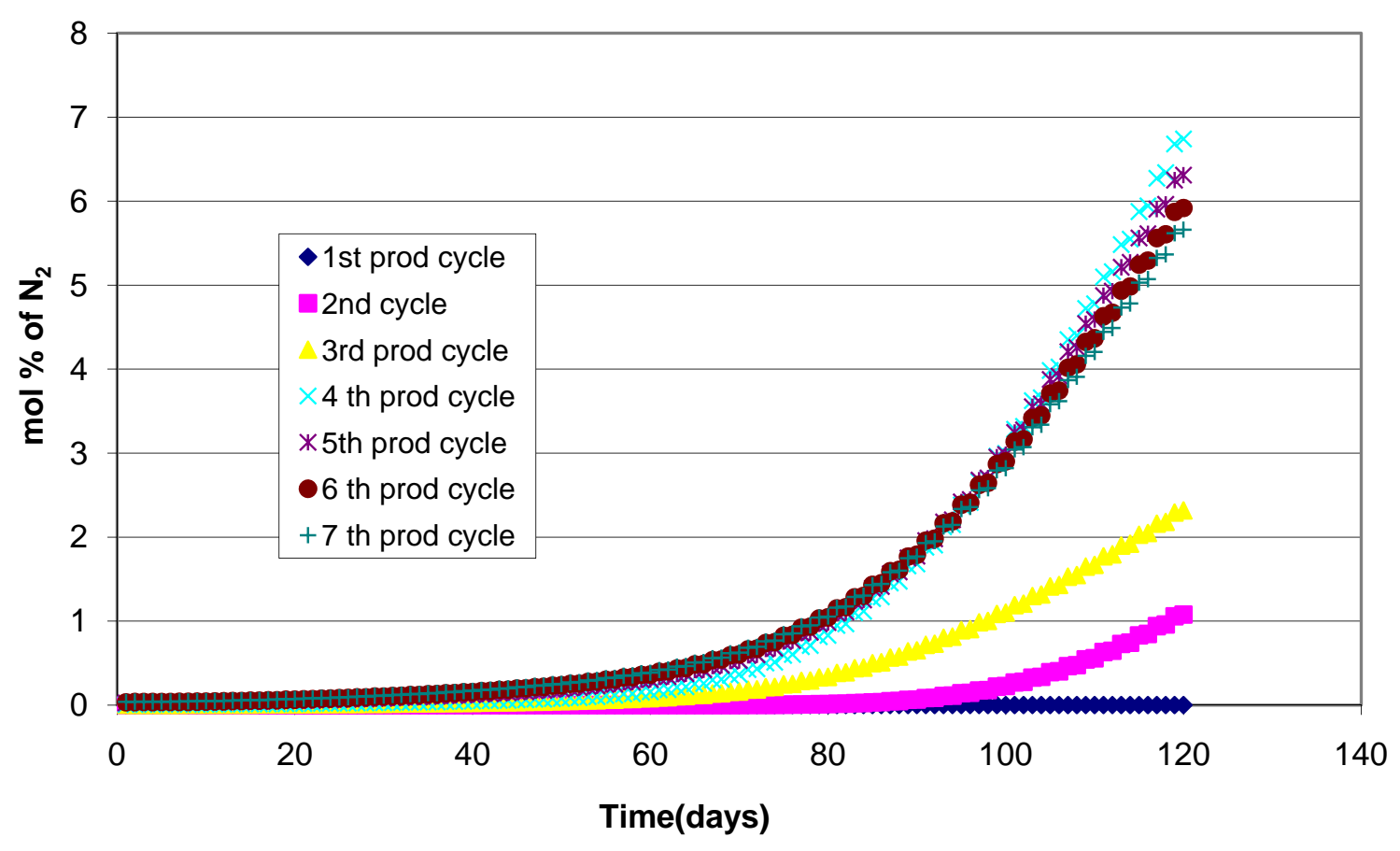

Figure 11- Mole \% of Nitrogen in the Withdrawn Gas (20\% $\mathrm{N}_{2}$ Injected by Volume)

\subsubsection{Effect of Pressure on Mixing in the Reservoir}

The results for Case 1 indicate that the pressure does not have great impact on mixing. If observed closely in Figures 12 and 13 we observe that for reservoir at 1000 psia the mixing takes place evenly when compared with the reservoir at 2000 psia. When these two systems are compared closely for each withdrawal cycle the minor change in concentration of nitrogen could be distinguished. 


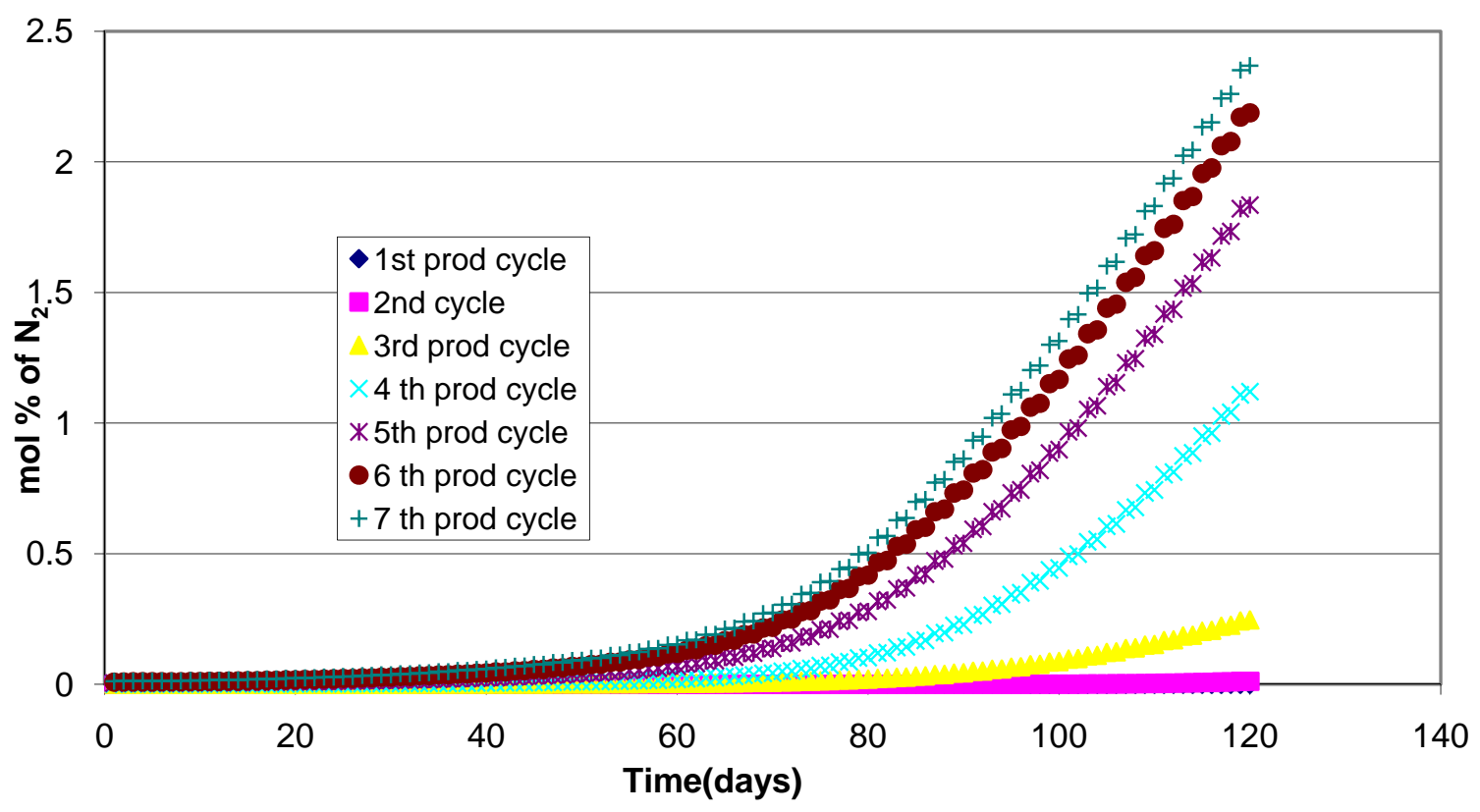

Figure 12- Mole \% of Nitrogen in the Withdrawn Gas $\left(10 \% \mathrm{~N}_{2}\right.$ Injected by Volume - Reservoir Pressure 1000 psia)

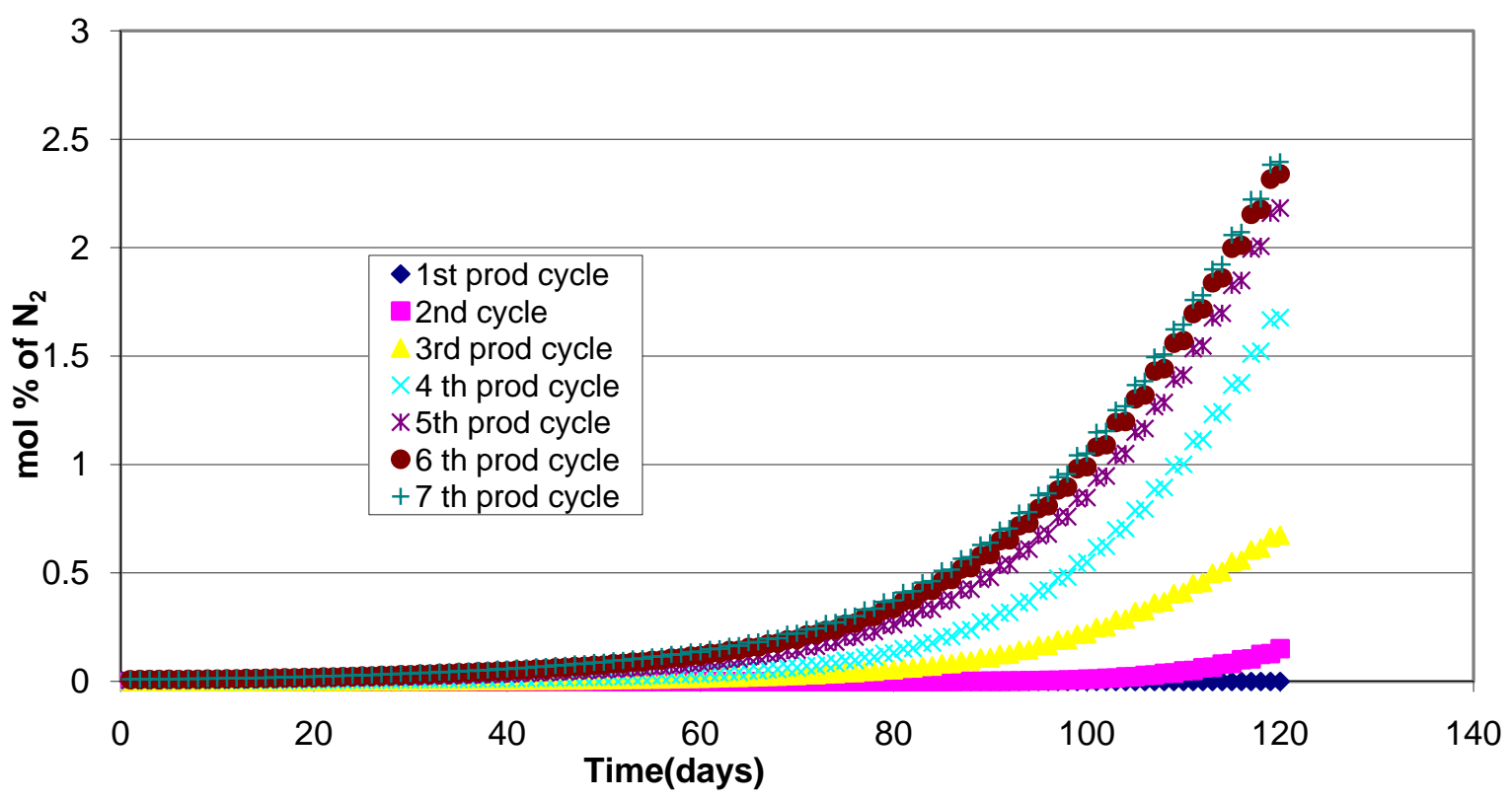

Figure 13- Mole \% of Nitrogen in the Withdrawn Gas $\left(\mathbf{1 0 \%} \mathbf{N}_{2}\right.$ Injected by Volume - Reservoir Pressure 2000 psia) 
The similar pattern is observed in case 2 as shown by graphical representation in Figures 14 and 15. If each withdrawal cycle is independently compared distinguishable features are noticed. Thus with an increase in the reservoir pressure there is slight increase in rate of mixing. The simulations performed for pressures at 1000 and 200 psia indicate that change in pressure would not affect the degree of mixing. The degree of mixing is very high when $20 \%$ nitrogen of total volume is injected in to a storage reservoir; therefore $20 \%$ replacement of total volume is not encouraged in further simulations.

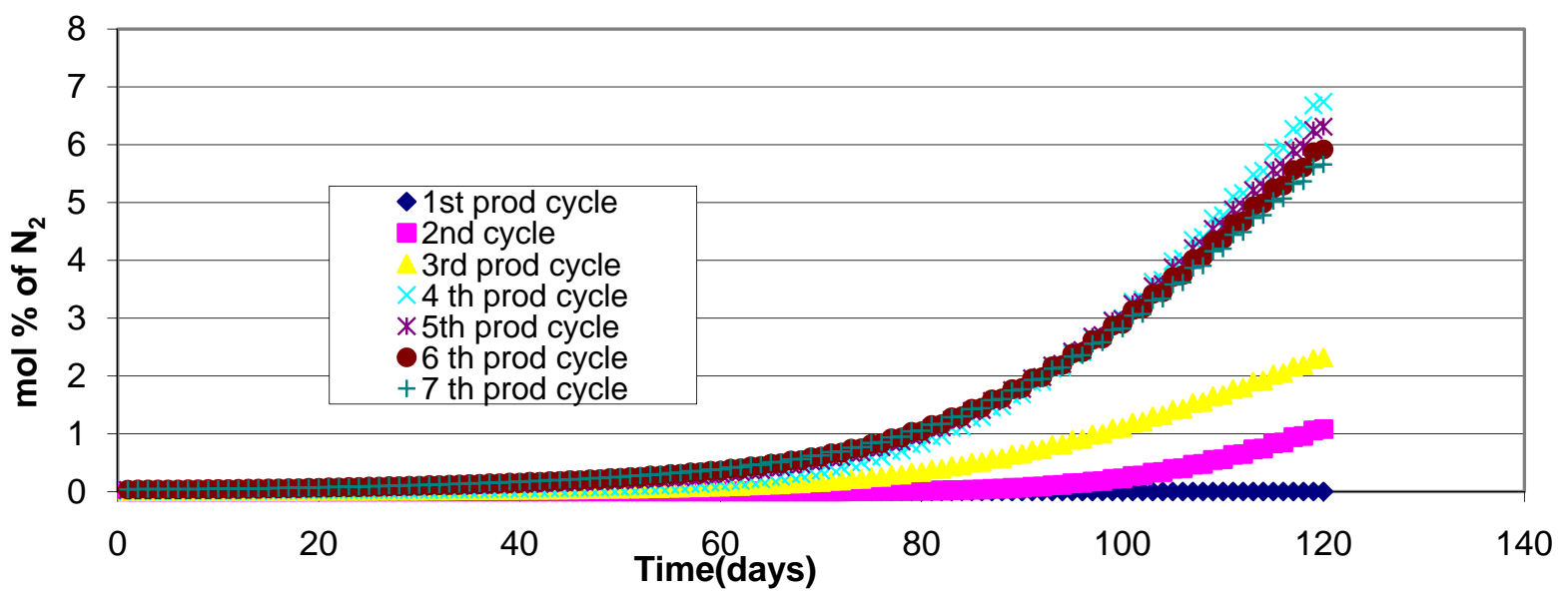

Figure 14- Mole \% of Nitrogen in the Withdrawn Gas $\left(20 \% \mathrm{~N}_{2}\right.$ Injected by Volume - Reservoir Pressure 1000 psia)

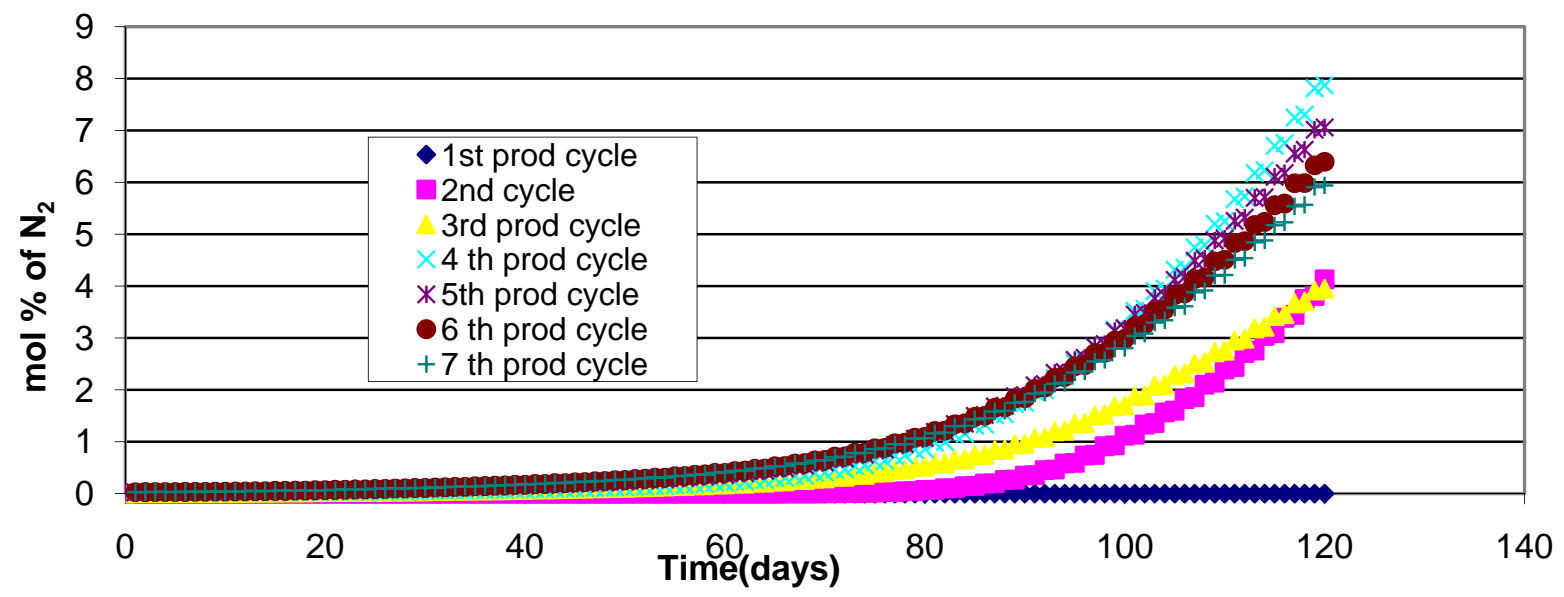

Figure 15- Mole \% of Nitrogen in the Withdrawn Gas $\left(20 \% \mathrm{~N}_{2}\right.$ Injected by Volume - Reservoir Pressure 2000 psia) 


\subsubsection{Effect of Porosity on Mixing in Reservoir}

The porosities of 10, 20 and 30\% were simulated and the volumes of nitrogen injected are adjusted according to the total volume of reservoir. Table 14 shows the nitrogen material balance before and after the withdrawal cycle for varying porosity.

Table 14 - Nitrogen material balance for different porosities

\begin{tabular}{|c|c|c|c|}
\hline Porosity & $\begin{array}{c}\text { Nitrogen injected in to } \\
\text { reservoir }\end{array}$ & $\begin{array}{c}\text { Nitrogen in the reservoir after } \\
\text { withdrawal cycles }\end{array}$ & $\begin{array}{c}\text { Nitrogen in the } \\
\text { withdrawn gas }\end{array}$ \\
\hline$\%$ & g-mol & g-mol & g-mol \\
\hline 10 & $1.25 \times 10^{8}$ & $1.18 \times 10^{8}$ & $6.91 \times 10^{6}$ \\
\hline 20 & $2.51 \times 10^{8}$ & $2.32 \times 10^{8}$ & $2.88 \times 10^{7}$ \\
\hline 30 & $3.76 \times 10^{8}$ & $3.48 \times 10^{8}$ & \\
\hline
\end{tabular}

The graphical representation in Figures 16, 17 and 18 shows that increase in porosity would increase the rate of mixing in the reservoir. The increase in the range of porosity from $20 \%$ to $30 \%$ does not see much of change in the overall mixing effect. The mixing in reservoir with $10 \%$ porosity concludes that mixing does not take place that effectively in low porosity reservoirs.

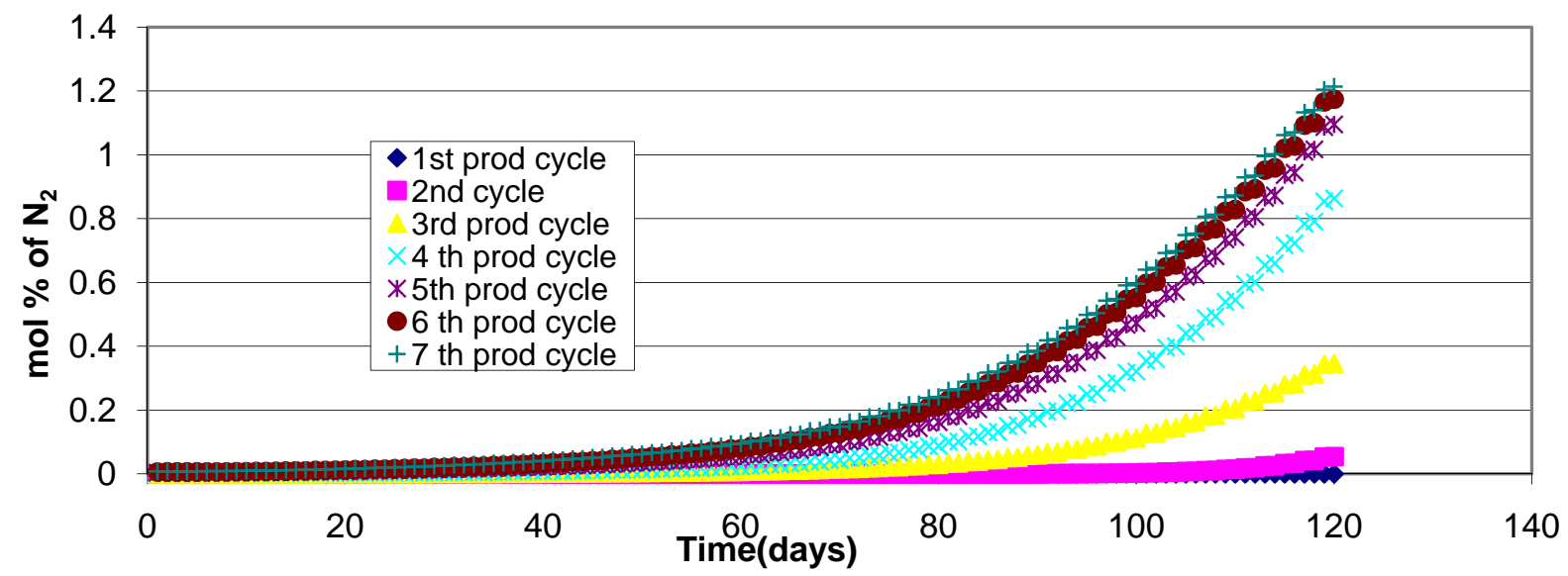

Figure 16- Mole \% of Nitrogen in the Withdrawn Gas - 10\% Reservoir Porosity 


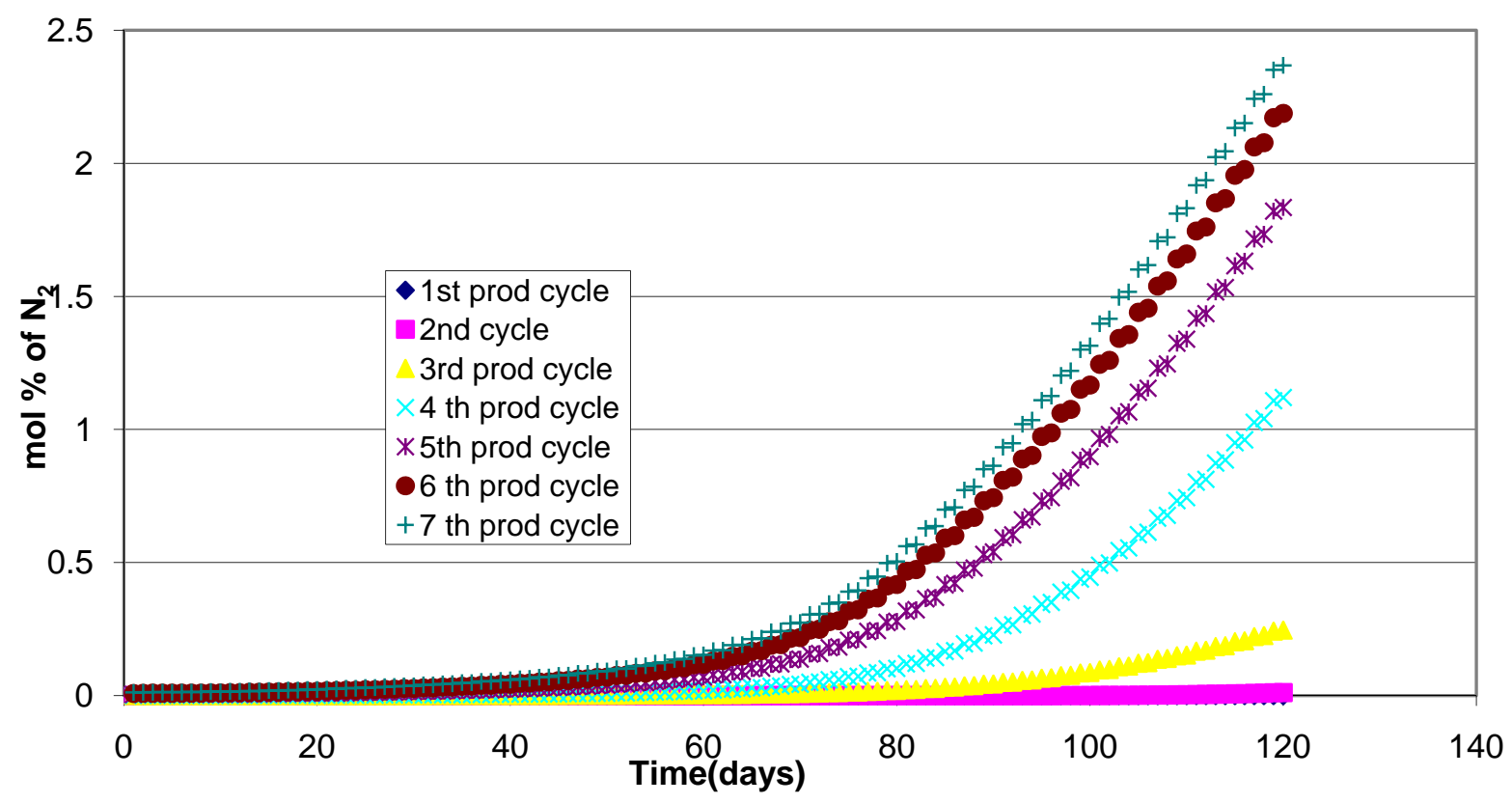

Figure 17- Mole \% of Nitrogen in the Withdrawn Gas - 20\% Reservoir Porosity

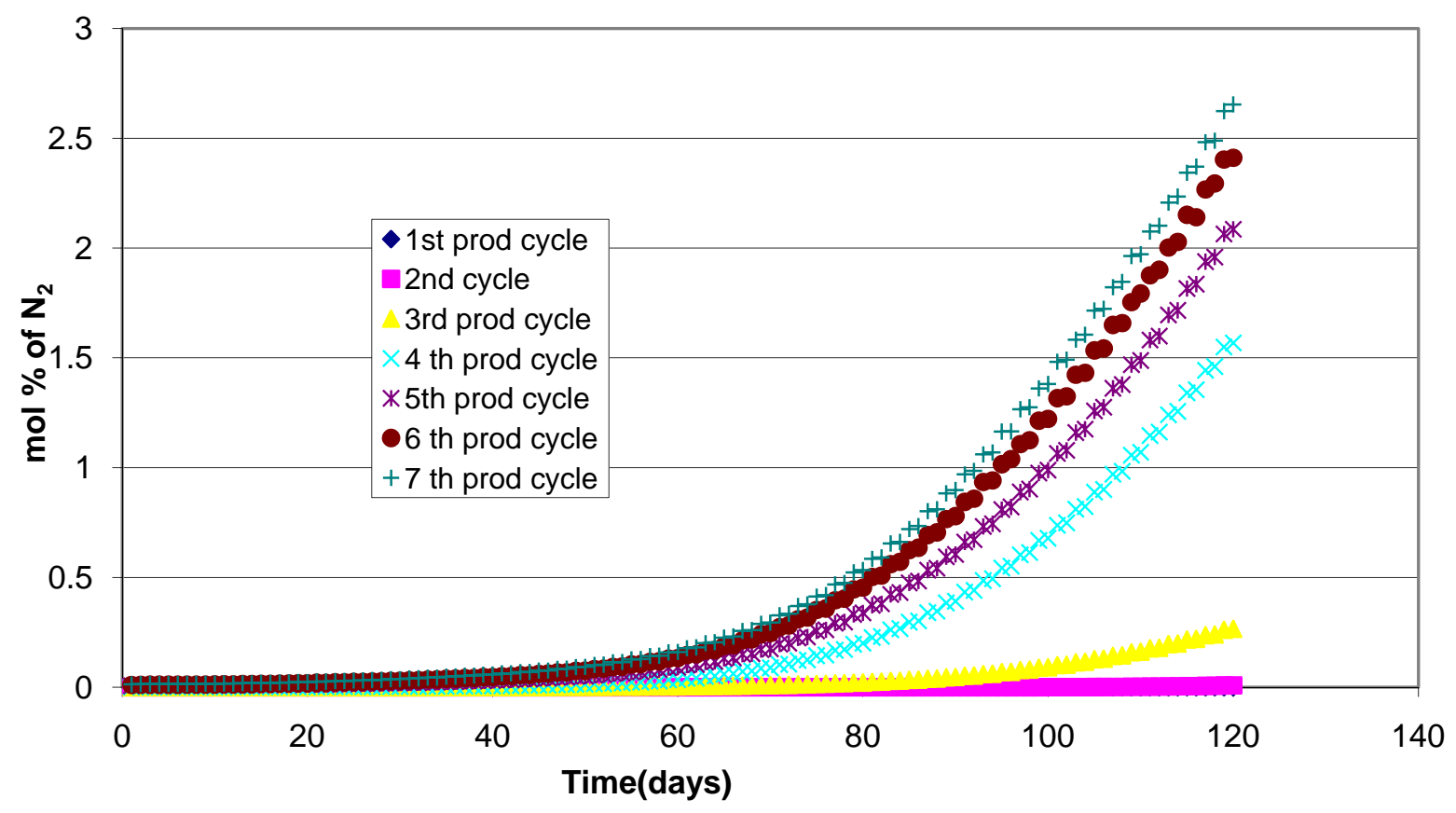

Figure 18- Mole \% of Nitrogen in the Withdrawn Gas - 30\% Reservoir Porosity 


\subsubsection{Effect of Permeability on Mixing in Reservoir}

The permeabilities of 100, 200 and 300md were simulated and the volumes of nitrogen injected are adjusted according to the total volume of reservoir. Table 15 shows the nitrogen material balance before and after the withdrawal cycles for varying permeability.

Table 15 - Nitrogen material balance for varying permeability

\begin{tabular}{|l|l|l|l|}
\hline Permeability & $\begin{array}{l}\text { Nitrogen injected in to } \\
\text { reservoir }\end{array}$ & $\begin{array}{l}\text { Nitrogen in the reservoir } \\
\text { after withdrawal cycles }\end{array}$ & $\begin{array}{l}\text { Nitrogen in the } \\
\text { withdrawn gas }\end{array}$ \\
\hline md & g-mol & g-mol & g-mol \\
\hline 100 & $2.51 \times 10^{8}$ & $2.32 \times 10^{8}$ & $1.88 \times 10^{7}$ \\
\hline 200 & $2.51 \times 10^{8}$ & $2.25 \times 10^{8}$ & $2.55 \times 10^{7}$ \\
\hline 300 & $2.51 \times 10^{8}$ & $2.23 \times 10^{8}$ & $2.84 \times 10^{7}$ \\
\hline
\end{tabular}

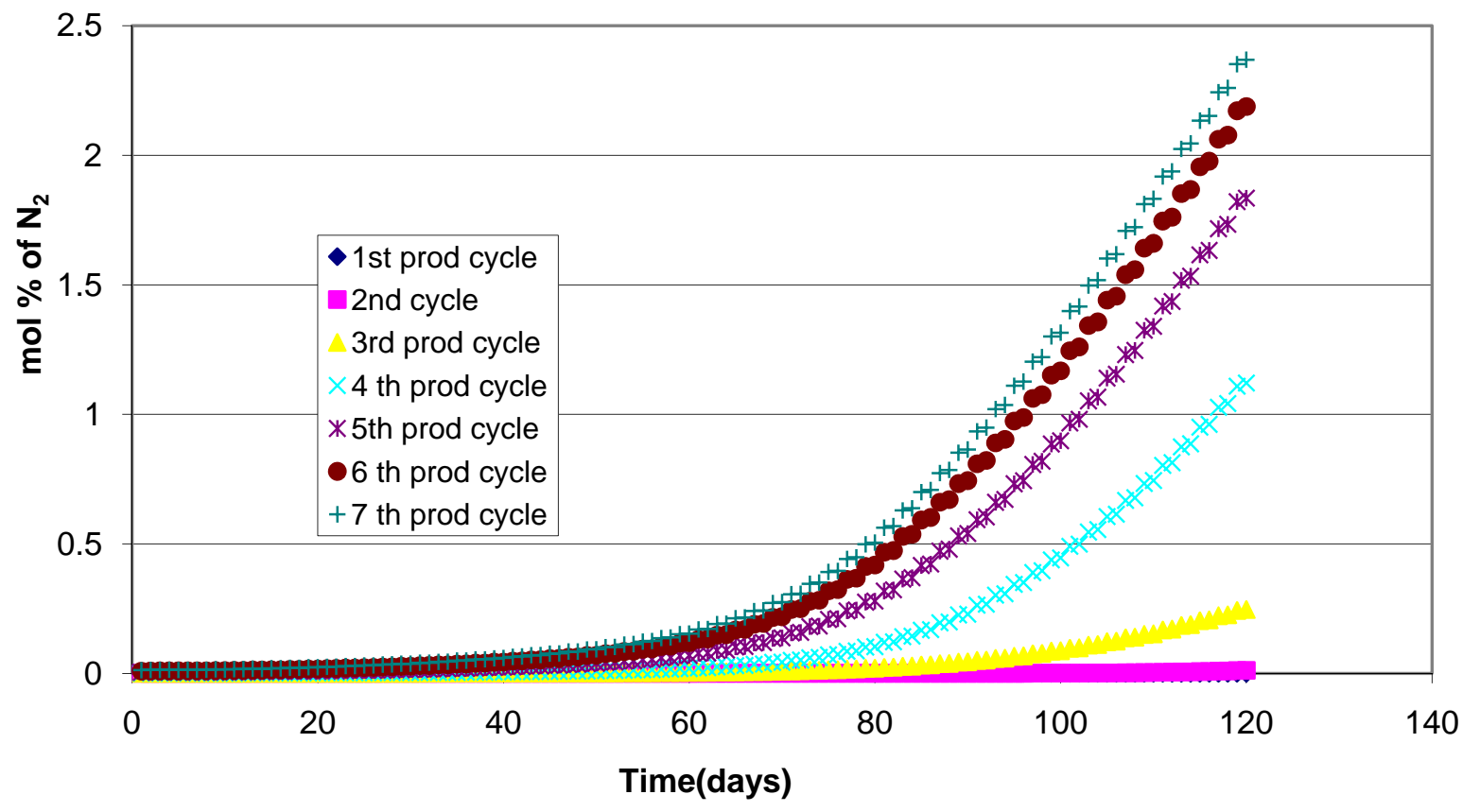

Figure 19- Mole \% of Nitrogen in the Withdrawn Gas - Reservoir Permeability 100 md 


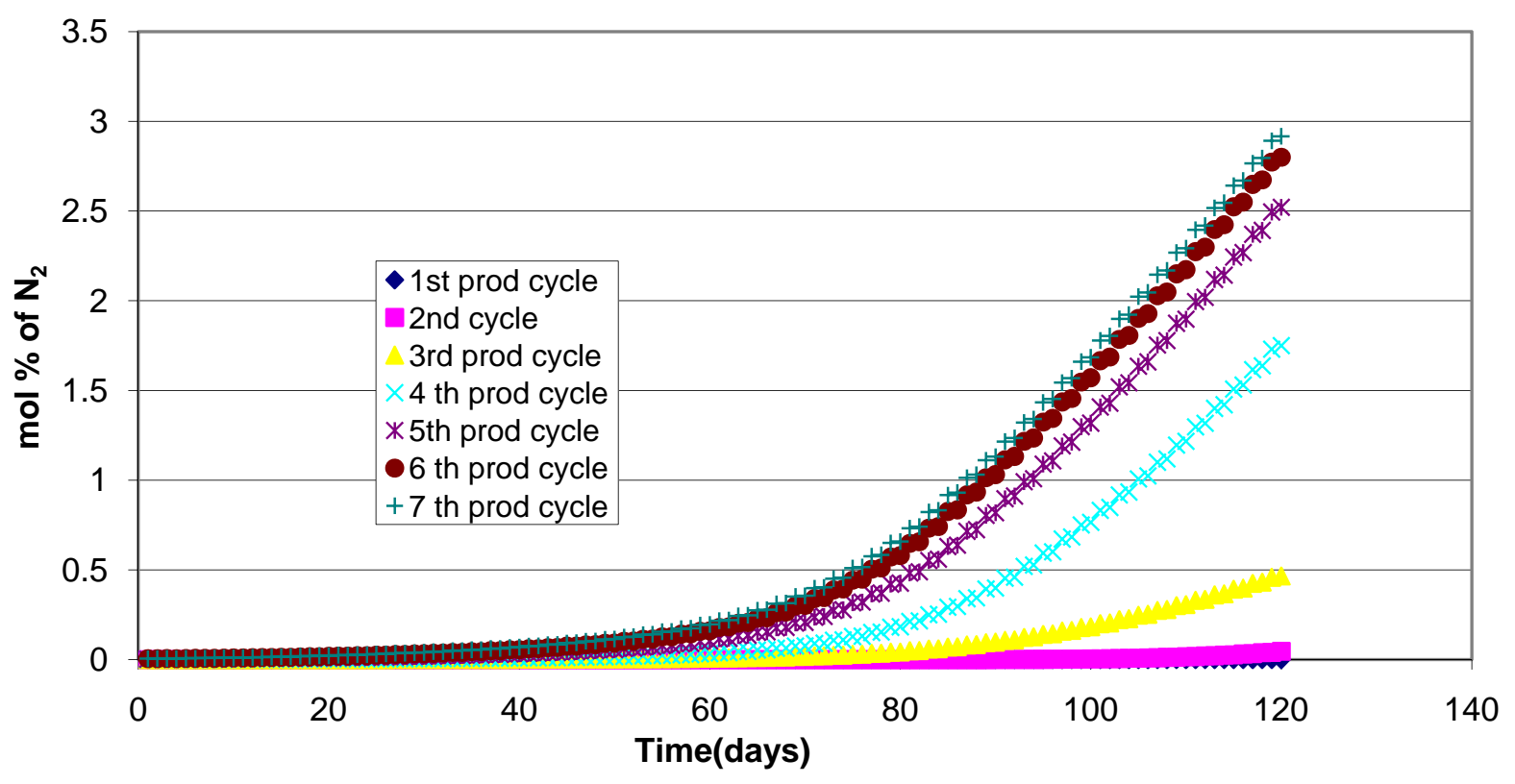

Figure 20- Mole \% of Nitrogen in the Withdrawn Gas - Reservoir Permeability 200 md

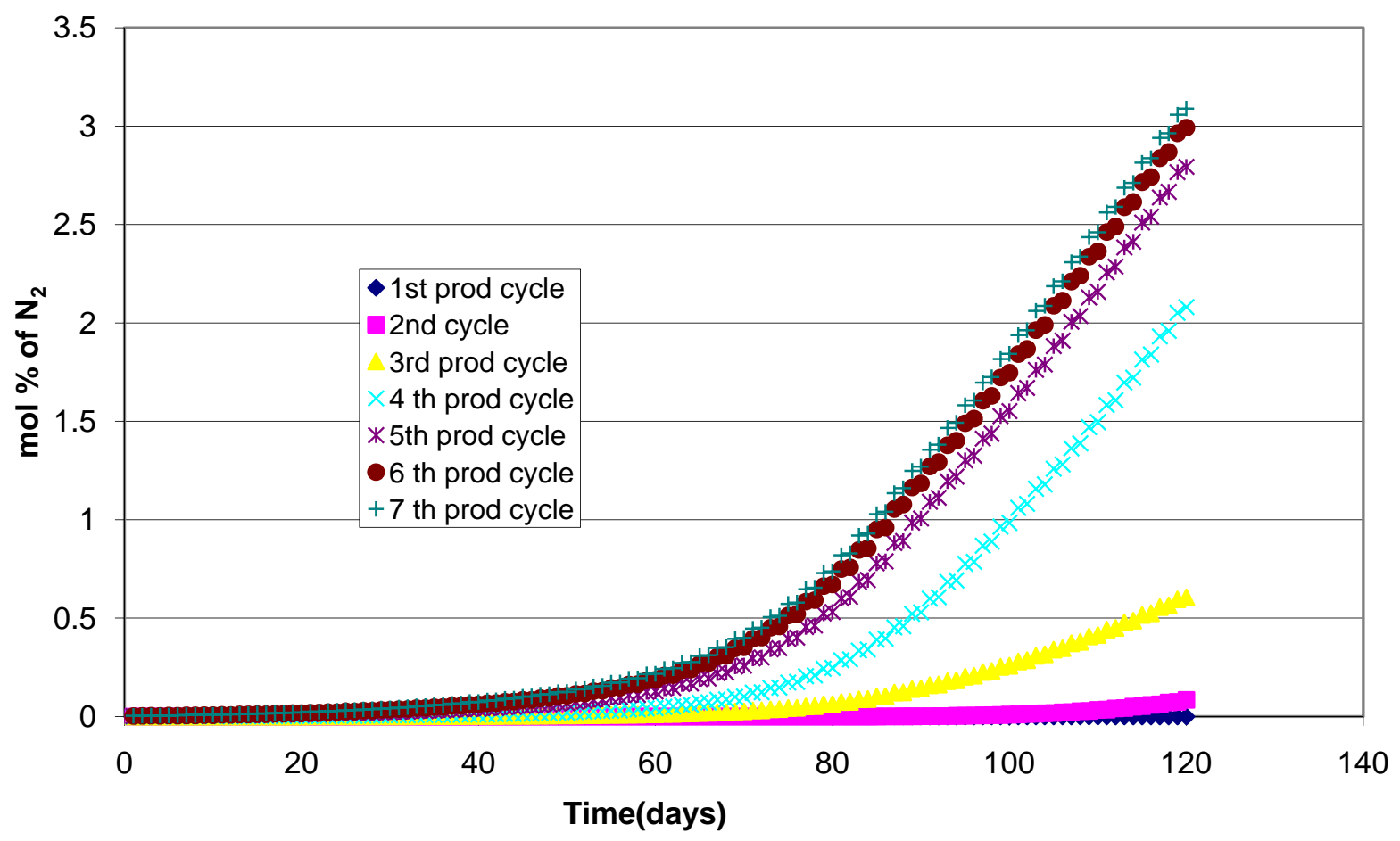

Figure 21- Mole \% of Nitrogen in the Withdrawn Gas - Reservoir Permeability 300 md 
The effect of permeability is not significant as we see in the Figure 19 with $100 \mathrm{md}$ permeability, initial withdrawal cycles show less mixing when compared to Figures 20 and 21 but with time the concentration of nitrogen in produced gas stabilizes. Due to the storage time involved the effect of permeability could be considered as negligible. The illustrated graphs indicate that the change in permeability does not show great impact on mixing in general. The increase in reservoir permeability from $100 \mathrm{md}$ to $300 \mathrm{md}$ is likely to see small increase in mixing trend.

\subsection{Distance variation between Injector and producer well}

Two models were developed by changing grid block size from $50 \mathrm{ft} \times 50 \mathrm{ft}$ to $100 \mathrm{ft} \times 100 \mathrm{ft}$. The objective in increasing in size of the grid block is to increase the distance between injector well and producer well.

\subsubsection{Reservoir with block size $100 \mathrm{ft} \times 100 \mathrm{ft}$}

A square shaped reservoir is built with 26 blocks on each side, and a block width of $100 \mathrm{ft}$. The volume of cushion replaced was $10 \%$ of total volume by injecting in two installments of $5 \%$ each time. Volume of nitrogen injected in to the reservoir and the withdrawal rate are modified as the total volume of the reservoir is quadrupled. The Table 16 below shows the nitrogen material balance before and after the withdrawal cycles.

Table 16 - Nitrogen material balance for increased block width of $100 \mathrm{ft}$

\begin{tabular}{|c|c|c|c|}
\hline Pressure & $\begin{array}{c}\text { Nitrogen injected in to } \\
\text { reservoir }\end{array}$ & $\begin{array}{c}\text { Nitrogen in the reservoir } \\
\text { after withdrawal cycles }\end{array}$ & $\begin{array}{c}\text { Nitrogen in the } \\
\text { withdrawn gas }\end{array}$ \\
\hline Psia & g-mol & g-mol & g-mol \\
\hline 1000 & $1.0 \times 10^{9}$ & $9.61 \times 10^{8}$ & $3.95 \times 10^{7}$ \\
\hline
\end{tabular}




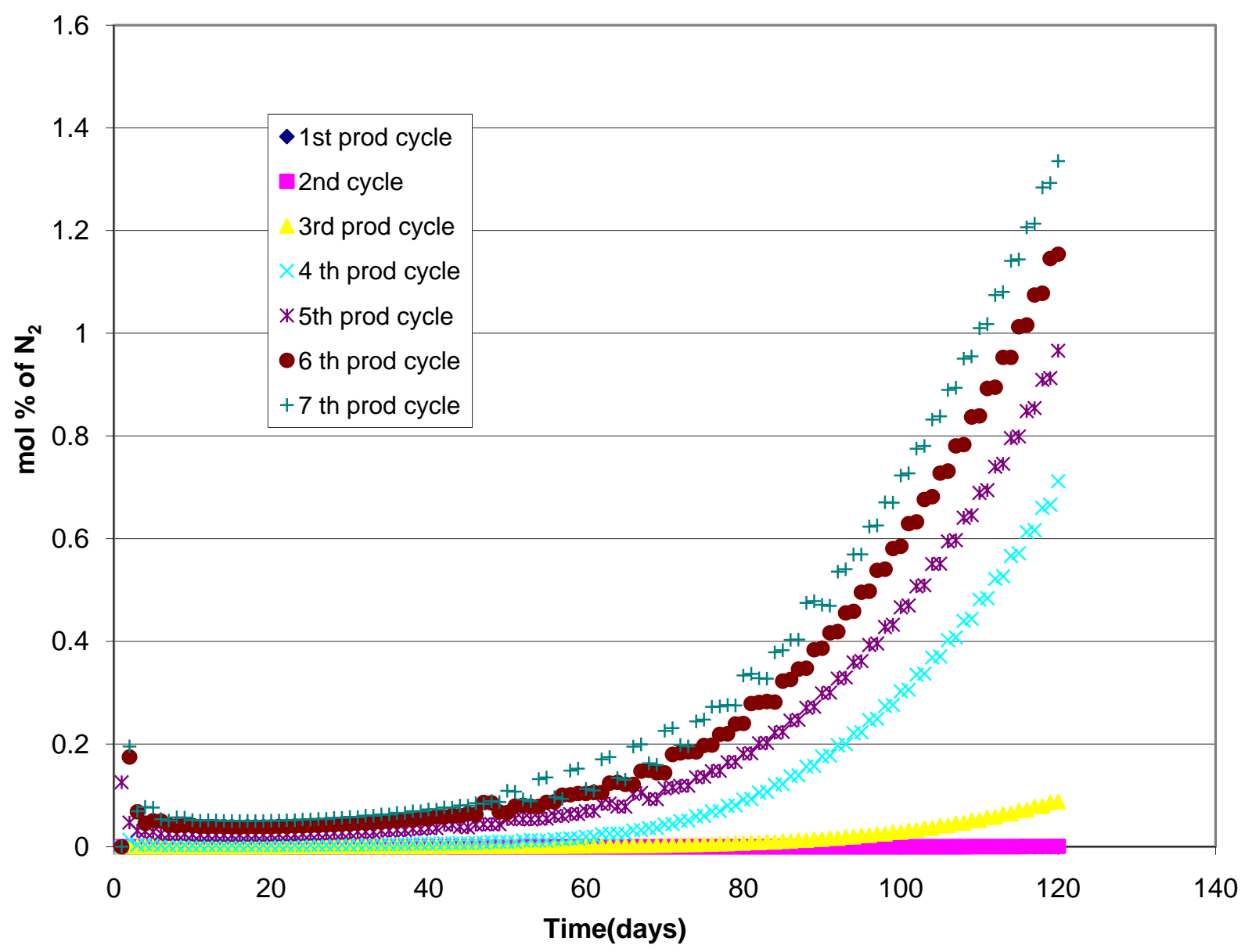

Figure 22- Mole \% of Nitrogen in the Withdrawn Gas (10\% N2 Injected into a Large Reservoir)

The graph in Figure 22 shows that concentration of nitrogen in the produced gas is decreased by increasing the size of reservoir. The distance between nitrogen injector and the producer well is increased by using a large area of reservoir. Nitrogen concentration remains low for 60 days and rapidly increases from there which was also observed in previous models. The maximum concentration of nitrogen in withdrawn gas at the end of 120 days is found to be $1.3 \%$. Increase in distance between injector and producer decreases the effect of mixing in a reservoir. 


\subsubsection{Rectangular Reservoir Grid with block size $100 \mathrm{ft} \times 100 \mathrm{ft}$}

A rectangular reservoir grid is built of the same volume corresponding to earlier model with 52 blocks on one side and 13 blocks on other side. Block size is $100 \mathrm{ft} \times 100 \mathrm{ft}$. The Table 17 shows the nitrogen material balance before and after the withdrawal cycles.

Table 17 - Nitrogen material balance for rectangular grid of same volume

\begin{tabular}{|c|c|c|c|}
\hline Pressure & $\begin{array}{c}\text { Nitrogen injected in to } \\
\text { reservoir }\end{array}$ & $\begin{array}{c}\text { Nitrogen in the reservoir } \\
\text { after withdrawal cycles }\end{array}$ & $\begin{array}{c}\text { Nitrogen in the } \\
\text { withdrawn gas }\end{array}$ \\
\hline Psia & g-mol & g-mol & g-mol \\
\hline 1000 & $9.51 \times 10^{8}$ & $9.47 \times 10^{8}$ & $3.55 \times 10^{6}$ \\
\hline
\end{tabular}

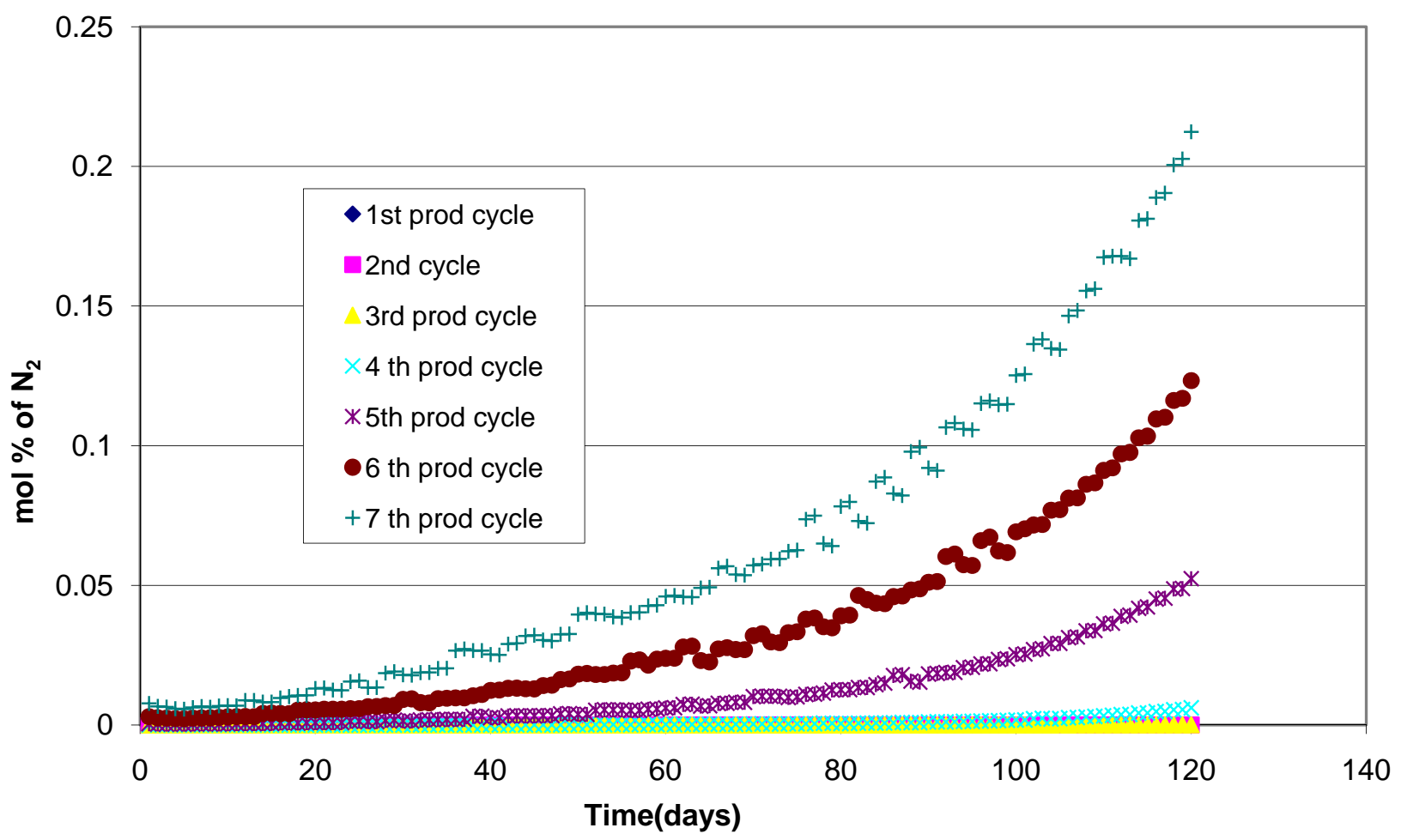

Figure 23- Mole \% of Nitrogen in the Withdrawn Gas (10\% N2 Injected into a Rectangular Reservoir) 
The results from Figure 23 imply that there is a great impact on mixing when distance between methane producer and the nitrogen injector is increased. The rectangular reservoir which is of same volume as of the square shaped reservoir reaches a maximum nitrogen concentration of $0.21 \%$ at the end of 120 days. The first 5 cycles of production see nothing or very little amount of nitrogen in the withdrawn gas. Equal volumes of nitrogen are injected in both the models but the nitrogen concentration seen in the rectangular model is very less when compared to the square reservoir model. The location of well from where the nitrogen is injected plays a major role in controlling the mixing effect in a storage reservoir. Nitrogen concentration decreases with the increase in distance between injector and producer 


\section{CONCLUSIONS}

The simulations conducted for time period of seven years on various models developed were analyzed to conclude the following

1. The degree of mixing is proportional to the percentage of inert nitrogen gas present as cushion.

2. The optimum percentage of cushion gas that can be replaced by inert substitute nitrogen is found to be 20 .

3. Proper placement of wells and injection patterns minimized mixing as a result.

4. Reservoir Pressure, Permeability, and Porosity had only minor impacts on degree of mixing.

5. Reservoir Pressure may affect the degree of mixing in initially but considering the long time periods involved in storage, reservoir pressure does not affect the mixing.

6. Comparing the various models simulated the distance between Nitrogen injector and Natural gas producer plays a major role in mixing of the two gases.

7. Injection of nitrogen in several stage provides for better control of mixing. 


\section{REFERENCES}

1) "Underground Storage of Natural Gas: Theory and Practice" Tek, Rasin M., Gulf publishing co. 1987

2) www.naturalgas.org

3) U.S Underground gas storage developments : 1998- 2005, EIA October 2006

4) American Gas Association "underground storage of gas in the U.S and Canada 1989, Engineering Technical Note, No. US -90-2-1, May 1989

5) Carbon dioxide as cushion gas for natural gas storage, Curtis M. Oldenburg (earth sciences division) 2002

6) Converting the Pe'corade oil field in to an underground gas storage, Philippe Coffin and Genevie've lebas TOTAL.

7) Mixing in Underground Storage Reservoirs by J.F.carriere and G.Fasanino, Gaz de France and M.R. Tek, University of Michigan. $60^{\text {th }}$ Annual conference SPE Las Vegas 1985

8) Simulation of underground gas storage, Research project: Partial differential equations in porous media, J. Molenaar.

9) The use of Inertgas as cushion gas in underground gas storage: Practical and Economic issues, Institute of gas technology

10) “Overview on Underground Storage of Natural Gas”; Katz, Donald L., Tek, Rasin M; University of Michigan., Journal of Petroleum Technology, June1981

11) Investigation of underground storage in a partially depleted gas reservoir, Reza Azin, Busher Iran; Amir Nasiri, Tehran Energy Consultants; Ali Jodeyri Entezari and Gholam hossien montazeri, University of Tehran SPE 113588,2008

12) Production of Inertgas for partial replacement opf Natural gas trapped in an underground Aquifer storage reservoir by L.C.berger and J.P. Arnoult Gaz de france SPE 19089, 1989

13) "Natural Gas Production and Storage", Katz, Donald. E, Mc Graw Hill company,1991

14) U.S storage drawdown analysis report, Energy Information Administration.

Oil and Gas office March 2008 
15) Underground Gas Storage : Issuses beneath the surface kanagana Dharmananda, Niel Kingsburg, Corrs chambers westgrath and Harnesh singh, Law school Universty of Western Australia, SPE 88491,2004

16) "Underground storage in Cerville-Velaine, France: A case history in conversion of inert gas unjection as substitute" Laille,J.p., Coulomb,c., Gaz de France; Tek,M.R university of Michigan. SpE 15588 New Orleans LA 1986

17) Simulation of underground gas storage in sarjeh field,Iran. Khamehchi, Amirkabir University of Technology( Tehran polytechnic), F. Rashidi SPE 106341, Saudi Arabia 2006

18) "Feasibility of Inert gas cushions in gas storage" U.S Department of Interior Bureau of mines, No. RI 6534, 1964

19) Long tern study of cushion gas replacement by inert gas, De Moegeb H.,Giouse,H., Gaz de France SPE19754 SPE TX 1989

20) Lantz R.B, “Quantitative Evaluation of Numerical Diffusion” SPE 2811 Dec 1969

21) Mass Transfer Operations Treybal, Robert E., Mc Graw Hill 1980

22) Modeling of mixed gas adsorption and diffusion in coal bed reservoirs. J.Q.Shi and S.Durucan, Imeprial College London. SPE 117172, 2008

23) Development and Application of Underground storage simulator, Mansanori Kurihara SPE, Jialing Liang, Japan Oil Energy Ltd, Fujio Fujimoto Japan National Oil corporation, Long Nghiem,SPE and Petrt Sanmon CMG Ltd. SPE 59438 Asia pacific conference April 2000

24) Gas Storage in a Depleted/Condensate Reservoir in the Applachian Basin. Aminian, k., Bannon,A., Ameri.S., SPE 104555 meeting Canton,Ohio 2006

25) "The impact of mixing inert cushion gas with natural gas in storage reservoir" Thesis report submitted to West Virginia University.( Advisor Dr. K.Aminian)

26) Computer Modeling Group Users manual GEM 2007.1 and Builder. 